\title{
Automatic Control of Human Thermal Comfort With a Liquid-Cooled Garment
}

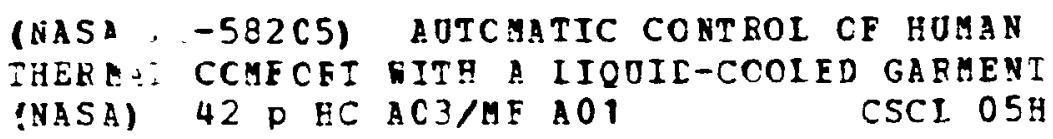

Space Shuttle Extravehicular Mobility Unit

Lawrence H. Kuznetz

Lyndon B. Johnson Space Center

September 1977

\section{N/Sก \\ National Aerondutios ind \\ Space Administration}

Lyndon B. Johnson Space Center

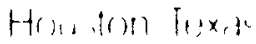


NASA TM 58205

AUTOMATIC CONTROL OF HUMAN THERMAL COMFIRT

WITH A LIQUID-COOLED GARMENT

Lawrence $H$. Kuznetz

Lyndon B. Johnsor. Space Center

Houston, Texas 77058 
CONTENTS

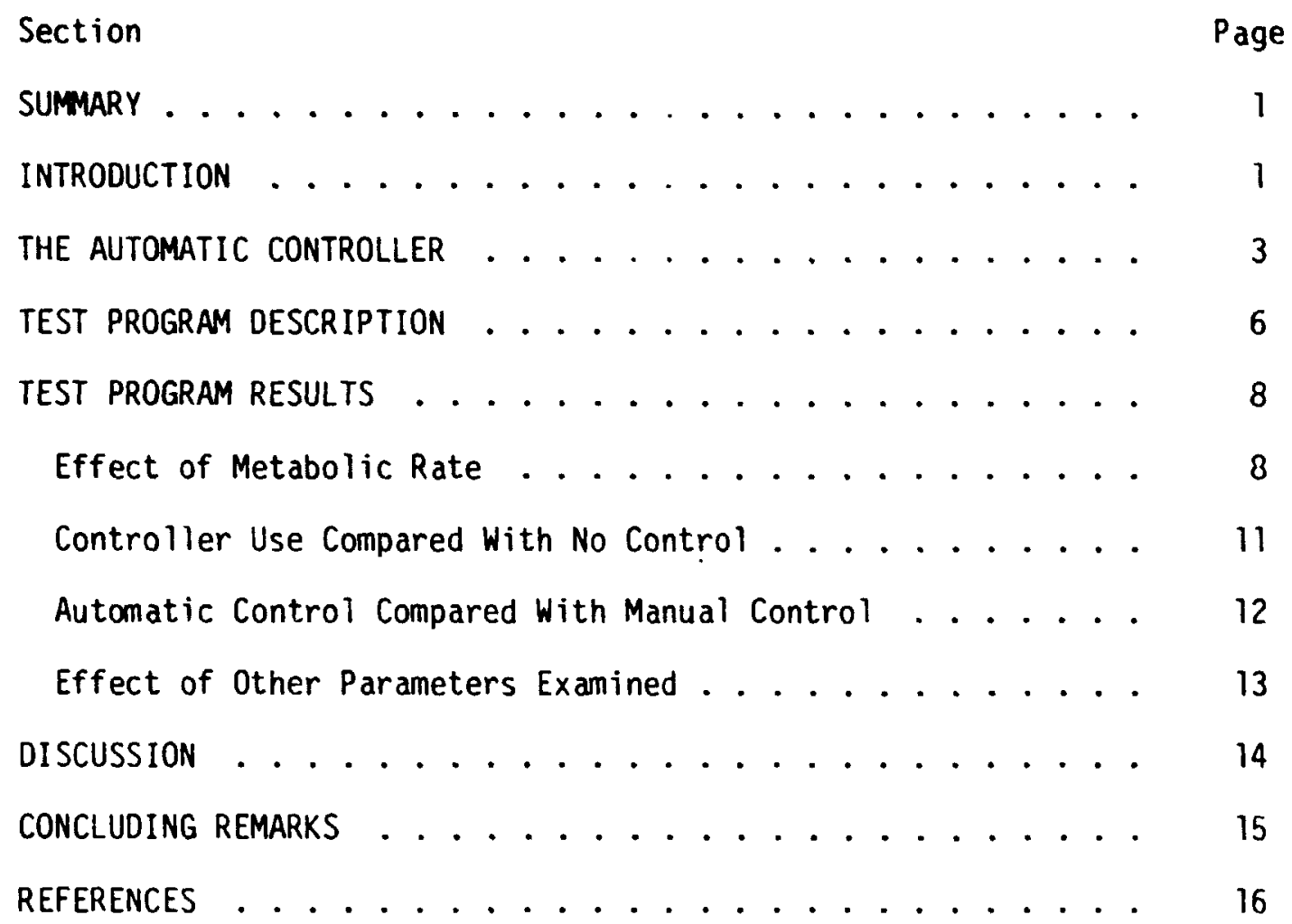




\section{FIGURES}

Figure

1 Prediction of LCG heat removal (or LCG $\triangle T$ ) , as a function of metabolic rate.......... 17

$2 \quad$ LCG inlet temperature in rel-tionship to LCG $\Delta T$ at the comfort level ........... 18

3 Change in LCG $\triangle T$ compared to change in LCG inlet temperature while comfort is tracked ....... 19

4 Equation derived for controller logic ....... 20

5 Total body heat balance equation, where $Q$ indicates

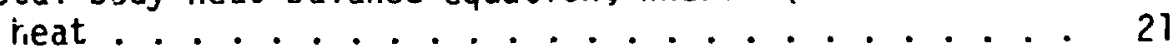

6 Test subject and instrumentation for measurements . . 22

7 Operational layout of the test control room ..... 23

8 Patterns of metabolic rate profiles over time

(a) Step ................ 23

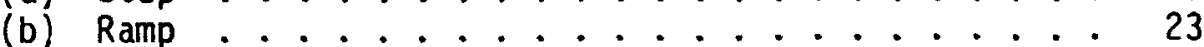

(c) Stress ................. 23

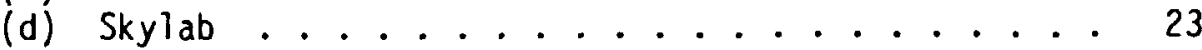

9 Performance of automatic controller (with LCG under space suit worn by subject $B$ ) for three metabolic profiles

(a) Metabolic rate .............. 24

(b) Comfort index with comfort zone shaded . . . . . 24

(c) Total body heat storage ........... 24

(d) LCG in let temperature ............ 24

(e) LCG heat removal rate ........... 25

(f) Evaporative heat removal rate ......... 25

(g) Body heat storage rate ........... 25

10 Performance of automatic controller (with LCG under space suit worn by subject A) for two metabolic profiles

(a) Metabolic rate ............... 26

(b) Comfort index with comfort zone shaded . . . . . 26

(c) Total body heat storage ............ 26

(d) LCG in let temperature ........... 26

(e) LCG heat removal rate . . . . . . . . . . 27

(f) Evaporative heat removal rate .......... . 27

(g) Body heat storage rate ............ 2 27 
11 Automatic controller performance compared with no control (at a constant in let temperature of $300 \mathrm{~K}$ $\left(27^{\circ} \mathrm{C}\right)$ ) during test runs by subject $B$ at a nominal square-wave profile

(a) Metabolic rate ............ 28

(b) Comfort index with comfout zone shaded ..... 28

(c) Total body heat storage . . . . ...... 28

(d) LCG inlet temperature ........... 29

(e) Evaporative heat removal rate ......... 29

12 Automatic contruller performance compared with no control (at a constant inlet temperature of $294 \mathrm{~K}$ $(210 \mathrm{C})$ ) during test runs by subject $A$ at a nominal square-wave profile

(a) Metabolic rate ........... 30

(b) Comfort index with comfort zore shaded ..... 30

(c) Total body heat storage ........... 30

(d) LCG inlet temperature ........... 31

(e) Evaporative heat removal rate ....... 31

13 Automatic controller performance compared with manual control during test runs at the Skylab EVA profile

(a) Metabolic rate ................ 32

(b) Comfort index with comfort zone shaded ..... 32

(c) Total body heat storage ............ 32

(d) LCG in let temperature ........... 32

(e) LCG heat removal rate ............. 33

(f) Evaporative heat removal rate ......... 33

(g) Body heat storage rate ............ 33

14 Body heat storage extremes with controller...... 34

15 Comfort index results

(a) With use of controller ........... 35

(b) Without use of controller......... 35

16 Latent heat extremes, with and without use of controller............... 36 
AUTOMATIC CONTROL OF HUMÄN THERIHAL COMEORT

\author{
WITH A LIQUID-COOLED GARMENT \\ By Lawrence H. Kuznetz \\ Lyndon B. Johnson Space Center
}

\begin{abstract}
SUMMARY
Like the crewmembers on Apollo and Skylab flights, the Space Shuttle crewmembers will wear a liquid-cooled garment to maintain the ir thermal comfort during extravehicular activity. During the earlier programs, manual control of the cooling water was necessary to maintain proper control of body heat storage. The development of an operational automatic therinal control system would relieve the crewmember of this task, which can interfere with his objectives. In this study, an analytical mudel of human tharmoregulation was used to develop the equations governing the operation of an automatic controller. The resulting controller operated without attachments to the body, using only the temperature difference in water going into and out of the garment. A series of tests, in which both objective and subjective data were collected on three subjects, demonstrated the ability of the controller to maintain a thermal balance both comfortable and within allowable medical limits.

Although the controller developed as a result of this study was designed for use with the Shuttle extravehicular mobility unit, it was found to function well in other applications and should be the simplest means possible for providing automatic control of thermal comfort for any ground-based application in which a liquid-cooled garment is used
\end{abstract}

\title{
INTRODUCTION
}

The liquid-cooled garment (LCG) is being rapidly accepted as a means of removing excess body heat that cannot be disposed of by normal environmental mechanisms. It was developed by the Royal Aircraft Establishment and the National .eronautics and Space Administration (NASA) in 1964 for the Apollo Program when it became evident that the heat generated by crewmen during extravehicular activity (EVA) could not be sufficiently removed by a gas-cooled space suit. The LCG is now being used for many other diverse purposes. These purposes include establishing constant skin temperatures during neurosurgery; cardiovascular research; cooling and reducing perspiration rates in surgeons during delicate operations; cooling race car urivers in the presence of high engine heat; cooling workers exposed to high furnace heat in steel, glass, and iron plants; warming divers descending to great depths; and inany other applications.

The LCG task is accomplished through the use of conductive cooling. However, a significant problem has been the control of LCG cooling in response to varying work rates. Webb (ref. 1) and Kuznetz (ref. 2) found a temporal dissociation between heat production and heat output of the LCG. 
This characteristic results in an obligatory period of body heat gain after the onset of work. The delay between heat production and steadystate heat removal by the LCG has been observed to be as long as I hour and may result in inefficient work performance and significant thermal stress. The problem can be lessened somewhat by increising the cooling just before beginning work or by very frequent adjustments in cooling temperature.

During the Apollo and Skylab Programs, there were instances of apparent undercooling and overcooling during lunar-surface and Skylab EVA's (ref. 2). Crewmembers tended to stay in the minimum or intermediate cooling range for long periods rather than make frequent adjustments. During the Apollo and Skylab Programs, the crewmen were supported by a real-time ground monitoring team that could advise the flight director to tell the EVA crewmen to increase or decrease their LCG cooling (ref. 3).

During the Space Shuttle Program, crewmembers will work without the benefit of a ground monitoring team to detect thermal imbalances. Because human subjects are poor judges of the ir own thermal status (ref. 4), these imbalances could be sustained for long durations, in which case discomfort, impaired efficiency, and heat storage buildup could result. The situation is aggravated further because crewmembers will be busier and more task oriented during Shuttle EVA's than they were during earlier EVA's and, therefore, much less likely to attend to LCô cooling adjustments.

A solution to this problem is the development and use of an automatic control system that would sense cremmember thermal comfort and automatically adjust LCG cooling to maintain it over a wide range of work rates. Such a controller would include a marual override to account for individual variations and environmental effects but, in essence, could be set at the beginning of an EVA and left alone thereafter, much the same as a thermostat in a house.

The idea of an automatic LCG controller is not new. Several controllers developed and built by Webb and Chambers have been tested and successfully demonstrated (refs. 5 and 6). However, all these controllers have one major drawback. They require measurement of one or more of the following physiological parameters: skin temperature, rectal or core temperature, heart rate, sweat rate, or oxygen consumption. Usually, this measurement is used as a feedback loop input to the controller electronics to regulate the LCG inlet temperature to provide a desired relationship between the measured parameter and the LCG heat removal, which is also ineasured. However, body instrumentation is cumbersome to use, prone to mecharical failures and error, difficult to implement in a system such as the Shuttle extravehicular mobility unit (EMU), and costly. For these reasons, even the simplest system to date, Webb's controller using rises in body skin temperature and water temperature, has been unacceptable for space applications.

For their efforts in this study, the author acknowledges the assistance of David Cook, James Waligora, Willi am Ayotte, and F. Story Musgrave, all of the NASA Lyndon B. Johnson Space Center (JSC). 
As an aid to the reader, where necessary the original units of measure have been converted to the equivalent value in the Systeme International d'Unités (SI). The SI units are written first, and the original units are written parenthetically thereafter.

\section{THE AUTOMATIC CONTROLLER}

A decision was made to investigate the feasibility of designing an automatic control system that would not require the use of any physiological measurements but, rather, only the LCG inlet water temperature and the temperature difference between the LCG inlet and out let water $(\Delta T)$. These parameters are advantageous in that interfaces with the human body are not required, other than the existing LCG tubes.

The controller logic that was developed is designed to use measurements of LCG inlet temperature $\left(T_{i n}\right)$ and $L C G \Delta T$ alone. Although other investigators have attempted to build a controller that uses the same information, they have been unsuccessful because of the inability to derive a transfer function that relates LCG heat removal data to metabolic rate for both the steady-state and transient cases. In this study, the elusive transfer function was derived by using a detailed mathematical model of the human thermoregulatory system to obtain theoretical results, including the thermodynamic interactions with the liquid-cooled garment and the environment, and then correlating the theoretical results with test data. The model used is the 41-Node Metabolic Man romputer program developed at JSC, which is in wide use throughout NASA, NASA support contractor companies, and other institutions (refs. 1 and 7 ). This computer program is a derivation of the original Stolwijk-Hardy thermoregulatory model (ref. 8), which has undergone significant refinements in order to account for the thermodynamic effects of the LCG, the space suit, and the environment. In addition, the number of body compartments or nodes has been increased to include right and left arms, legs, hands, and feet. Considerable effort has been spent in deriving and correlating relationships for respiratory and insensible heat loss, as well as LCG and environmental interactions, including simulation of the convective, evaporative, and radiative heat transfer processes that occur between a man and his environment, be it a space suit or a shirtsleeve-temperature room. The mathematical model has been in use for several years and has been cont inuously refined and correlated with NASA test data to the point that it is now an operational tool in the analysis of all NASA man/system interfaces. It is especially accurate in predicting the performance and thermodynamic effects of the LCG.

For an automatic LCG controller to work, it must first sense some signal proportional to metabolic rate or heat production and then adjust the $L C G$ inlet temperature or flow rate to vary the LCG heat removal according to the metabolic rate or body heat content. It is not sufficient to design a controller that simply maintains a constant out let water temperature or $a$. Ists the heat removal to remove the incremental heat added to the LCG. These methods are unsatisfactory because only a percentage of the metabolic heat is reflected by an increasing LCG $\triangle T$. Because this percentage is an unknown variable, fixing the jutlet temperature or 
removing only that heat added to the LCG can lead to unacceptably high sweat rates, heat storage, and/or thermal discomfort. Use of the mathematical model made it possible to derive a relationship between the LCG inlet temperature and the LCG $\triangle T$ at comfort for both transier.t and steadystate cases without the necessity of knowing the metabolic rate, the body heat storage, or some other physiological parameter proportional to the latter. In other words, the model permits the derivation of an implicit technique for relating metabolic rate to LCG inlet temperature at comfort.

The steady-state relationship between the LCG inlet temperature and LCG heat removal at comfort for various metabolic rates is shown in figure 1. This curve has been derived from empirical data obtained in a thermally neutral environment with a constant LCG flow rate of $109 \mathrm{l} / \mathrm{hr}$. For other conditions, such as variable LCG flow rates at constant in let temperatures or thermally hot or cold environment, the results are somewhat different but predictable with use of the mathematical model (ref. 2).

Figure 1 was derived by using the environmental conditions as input to the mathematical model and varying metabolic rate and LCG inlet temperature as additional inputs. Steady-state predictions of LCG heat removal and total body heat storage were generated. Predictions of LCG heat removal (or LCG $\Delta T$ ) are shown in figure 1 as a function of metabolic rate. Lines of constant LCG inlet temperature corresponding to $278,283,289,294$, and $300 \mathrm{~K}\left(5^{\circ}, 10^{\circ}, 16^{\circ}, 21^{\circ}\right.$, and $\left.27^{\circ} \mathrm{C}\right)$ are also shown. The total body heat storage predictions appear alongside these lines at metabolic rates of $146,234,352,469$, and 586 watts. A comfort band was then superposed on figure 1 by simply connecting the appropriate value of heat storage corresponding to comfort at each metabolic rate.

The comfort band was derived by relating the subjective comments of test subjects wearing an LCG to measured values of their body heat storage (ref. 2). The range of the band was determined by noting that subjective variation in individual comfort assessment could be correlated with a rectal temperature increment range of $+0.3 \mathrm{~K}\left(+0.3^{\circ} \mathrm{C}\right)$, which corresponds to a range of +68.4 kilojoules ( +19 watt $t$-hour $\bar{s})$ in body heat storage. In previous tests, sweat rates for subjects conforming to the band have been limited to values between 0 and $100 \mathrm{~g} / \mathrm{hr}$. The band varies linearly from $0+68.4$ kilojoules $(0+19$ watt-hours $)$ of stored body heat at a metabolic rate of 146 watts $\overline{\text { to }} 144.0+68.4$ kilojoules $(40+19$ watt-hours $)$ at a metabolic rate of 586 watts. It has been in use at JST for a number of years and has proved an effective and accurate method of quantifying thermal confort.

When the appropriate values of confort heat storage for each metabolic rate in figure 1 are connected, a zone of values of LCG inlet temperatures and LCG $\triangle T$ 's is generated tnat limits heat storage to the comfort band. Values above this comfort zone correspond to uncomfortably cold conditions (including shivering for large deviations), and values below the band correspond to uncomfortably hot conditions (accompanied by excessive sweating for large positive values of heat storage). This comfort zone has been correlated with considerable test data ( $r \in f .2)$ and has been shown to conforin with other comfort zone criteria available in the literature, such as those postulated by Webb, Waligora, and Chambers (refs. 5, 6, 9, and 10). If figure 1 is now replotted by cross-plotting 
the LCG inlet temperatures conforming to the comfort zone with the corresponding LCG $\triangle T$ 's, the desired steady-state transfer function is derived. This new plot is shown in figure 2 .

An initial evaluation of this control scheme was then performed analytically by using the 4l-Node Man computer program. A typical metabolic profile with several step changes in work rate was input to the model, together with the initial LCG inlet temperature considered comfortable. The model then computed the corresponding LCG $\Delta T$, which was used in figure 2 to compute a new $T_{\text {in }}$. This procedure was repeated in time unt $i 1$ the entire metabolic profile was marched through. The results showed that the relationship shown in figure 2, by itself, was unstable for all but the most slowly changing conditions. In other words, it was acceptable for quasi-steady-state situations but was inadequate during rapid transients such as large-step changes in metabolic rate.

It then became necessary to derive a second transfer function to accommodate transients for these periods. This task was accomplished by imposing a series of step changes in input metabolic rate on the 41-Node Metabolic Man computer program and letting the prigram iteratively select an LCG inlet temperature that would limit the computed body heat storage to the heat-storage-based comfort band previously discussed. The model would select an inlet temperature at each metabolic rate and calculate a value of heat storage at each time step. It would then compare the calculated value of heat storage with the desired comfort value and iterate until it determined the correct value of inlet temperature required for staying within the comfort zone for each time step during the transient. The change in inlet temperature during each step in the transient was then plotted against the corresponding change in LCG $\triangle T$. This result is shown in figure 3 and represents the required transfer function for selecting changes in inlet temperature that correspond to thermal comfort during a trinsient, based on the observed changes in LCG $\Delta T$. When the curves of figures 2 and 3 were combined and then imposed on the 4l-Node Man computer program, tive model was able to limit the calculated heat storage to the comfort band for a representative range of stidy-state and transient conditions. It then remained to add additional refinements and variations to fine-tune the control scheme, including a derivative, an integral term, and appropriate gain constants. The final controller equation is shown in figure 4. It consists of two components, a steady-state part and a rate-of-change part. The steady-state part lises the existing value of LCG $\Delta T$ and calculates a new inlet temperature from figure 2. This new inlet temperature is multiplied by the gain constant, $K_{l}$, and added to the old inlet temperature to determine the steady-state contribution. The transient transfer function is found by first computing an error func. tion, $E$. The error function is the difference between the actual change in $\Delta T$ resulting from a change in inlet temperature $(\Delta(\Delta T) \mathrm{act})$ and the expected change in $\Delta T$ from figure $3\left(\Delta(\Delta T)_{\text {exp }}\right)$. The error term is inultiplied by a gain constant, $K_{3}$, and added to two more tems representing the time rate of change of the error signal and the time integrated value of the error signal with their appropriate gain constants $K_{4}$ and $K_{5}$. The sum of these three terms is then used in figure 3 as the ordinate, and the change in inlet temperature for comfort, $\Delta T_{i n}$, is the correspondinly abscissa. This $\Delta T_{\text {in }}$ is then multiplied by 1 ts weighting factor, $K_{2}$, and added to the steady-state term to determine the final $T$ in for comfort. 
The gain constants $K_{1}, K_{2}, K_{3}, K_{4}$, and $K_{5}$ were determined entirely by trial and error with use of the 41 -Node Metabolic Man program. The derivative and integral values, $K_{4}$ and $K_{5}$, are extremely small and play a minor role in the control scheme. The constant $K_{l}$ is small compared to $K_{2}$ and $K_{3}$. All the constants were derived on an entirely theoretical basis with use of the mathematical model. The controller scheme was then tested under actual, rather than simulated, conditions to establish its validity.

\section{TEST PROGRAM DESCRIPTION}

The controller test program consisted of 21 experiments in which three subjects were exercised at metabolic rates ranging from rest to vigorous activity ( 100 to 620 watts or more) while wearing an LCG under one of three overgarments, at room temperature. The garments consisted of an Apollo A7LB space suit, an arctic thermal suit with ventilation, and a simple pair of flight coveralls. All tests were conducted at sea-level pressure in a 2.4-meter-diameter ( 8 foot diameter) hypobaric chamber of the Crew Systems Laboratories at JSC.

The tests were 1 to 2 hours ir. duration and data were collected continuously. All tests were conducted with the usr of an LCG water fiow of either 109 or $521 / \mathrm{hr}$ and an inlet temperature that ranged between 279 and $302 \mathrm{~K}\left(6^{\circ}\right.$ and $\left.29^{\circ} \mathrm{C}\right)$.

Metabolic rates were controlled by varying the speed of a motordriven treadmill that the subjects had previously used in establishing a treadmill speed-subject metabolic rate profile. In addition, the metabolic rates were estimated and verified during each test by means of the total body heat balance equation ( $f i g .5$ ) and by comparison with predetermined calibration curves of heart rate in relation to metabolic rate.

The test subjects were one NASA astronaut, one other male, and one female. All subjects were in good physical condition and were familiar with the use and operation of the LCG. Their physical characterictics were as follows.

\begin{tabular}{|c|c|c|c|c|}
\hline Subject & Sex & Age, yr & Height, $m(i n)$. & Weight, $\mathrm{kg}$ (10) \\
\hline A & Male & 41 & $1.8(70)$ & $72.6(160)$ \\
\hline B & Male & 40 & $1.8(70)$ & $70.3(155)$ \\
\hline C & Female & 22 & $1.6(64)$ & $59.0(130)$ \\
\hline
\end{tabular}

The ventilating gas through the A7LB space suit and the arctic thermal garment was supplied by the chamber environmental equipment and consisted of air circulated at $170 \mathrm{1} / \mathrm{min}$ and maintained at a temperature of $295 \mathrm{~K}\left(22^{\circ} \mathrm{C}\right)$ and a dewpoint of $286 \mathrm{~K}\left(13^{\circ} \mathrm{C}\right)$. The air supply to the suit and the water supply to the LiG were open loop (not recirculated). 
The air and LCG outlet temperatures were measured by thermistors and recorded continuously. The air and water flow rates were also measured, as were the suit inlet and outlet dewpoints. The latter measurements were used to continuously determine LCG, convective, and evaporat ive heat removal rates during the test.

Three inner and three outer suit thermocouples were installed on the A7LB space suit at the chest, back, and leg areas to continuously monitor suit temperature. These temperatures, tonether with measurements of chamber wall and air temperatures, were used to calculate radiation heat loss from the skin, net convective and radiative heat loss from the suit to the chamber environment, and net heat loss through the suit. in addition, two space heaters were used to control the ambient temperature tr limit the heat loss through the suit to desired values.

A biomedical harness was used to measure hody skin temperatures in several areas, including the forehead, chest, arins, legs, and back. Copperconstantan thermocouples were used for these measurements. A rectal temperature thermistor and electrocardiograph sensors were also included in the biomedical harness to measure rectal temperature ani heart rate. All these temperatures were recorded continuously (fig. 6) and used to determine and plot total body heat storage and heat storage rate on a real-time bas is at 2-minute intervals. The other previously described recorded parameters were also plotted in real time and were used to compute terms in the total body heat balance equation. Subject mechanical work efficiency was determined from previous calibration runs on the treadmill to be approximately 12.5 percent. This value was also used in the total body heat balance equation for computing body heat storage rate and back-calculating metabolic rate.

During each test, the subject was requested to evaluate his feelings of comfort and thermal sensation on the following scale of 1 to 7 .

$$
\begin{array}{ll}
1 & \text { Cold } \\
2 & \text { Cool } \\
3 & \text { Slightly cool } \\
4 & \text { Neutral } \\
5 & \text { Slightly warm } \\
5 & \text { Warm } \\
7 & \text { Hot }
\end{array}
$$

This evaluation included sensory estimations for individual areas such as the limbs or extremities, as well as whole-body sensations.

For each test run, the LCG inlet. temperature was either determined by the controller logic, manually controlled by the subject according to his preference, or fixed at a constant value. The controller logic was implemented in an open-loop fashion because this test program was a feasibility 
study to verify an analytical theory rather than a test of actual controller hardware. The measured values of LCG inlet temperature and LCG $\triangle T$ were presented for display on a cathode-ray tube (CRT) in the test control room. These data and their recorded times were than manually input into a Wang 2200 microprocessor computer, which used them in a computer program containing the control logic equations. The computer then instantaneously displayed the desired LCG inlet temperature for comfort on another CRT. This new $T_{\text {in }}$ was then manually selected by the LCG water temperature operator at the requsest of the computer operator on a separate communication link (fig. 7). Although t!.ere are four separate loops between the measurement of the LCG $\Delta T$ and the actual implementation of a new $T_{i n}$, complete data could be input every 10 seconds and avoraged, with implementation of the desired $T_{\text {in }}$ occurring within $1 \mathrm{~m}$, ste. This totil lag time of I minute was chosen to simulate the actual system response time constant of the proposed Space Shuttle EMU (consisting of the LCG, the portable life-support system, and the space suit). It is evident that an actual controller would perform significantly better than this open-loop digital method because it would sample data continuously and make continuous, fine adjustments in LCG cooling rather than discrete, coarse adjustments.

\section{TEST PROGRAM RESULTS}

The primary results for the test program are presented in figures 8 to 13. These figures are arranged to examine, in order, the following considerations: the effect of metabolic rate, the comparison between controller use and no control, and the comparison between automatic control and manual control. In addition, other factors were examined during the test program, including the effect of heat loss to the environment, the effect of different water flow rates, the effect of test subject variabil$i t y$, the repeatability of test results, and the effect of different suits or covering garments.

\section{Effect of Metabolic Rate}

For this study, four different metabolic rate profiles were used: a nominal square-wave profile, a nominal ramp profile, a stress profile, and the Skylab 2 EVA profile (fig. 8). The nominal profiles were designed to sillulate normal work tasks anticipated during the Space Shuttle Program, whereas the stress profile was designed to te an off-nominal test for providing information about controller behavior when the LCG was overtaxed. (Any metabolic rate greater than 580 watts exceeds the rated capacity of the Apollo LCG to sustain comfort.) The Skylab 2 EVA profile was a duplication of the actual metabolic wor! loads experienced during deployment of the disabled solar panels on the first manned Skylab mission. This particular profile is extremely applicable because it represents actud peak work tasks that will be encountered during construction and repair tasks in space. To provide a realistic experience base, an asironaut test subject was used for the Skylab EVA profile.

Figures 9 and 10 provide data on the performance of the controller for the aforementioned metabolic profiles. Figure 9 is for subject $B$ wearing 
the Apollo A7LB suit with the LCG flow set at $109 \mathrm{l} / \mathrm{hr}$. The results shown are for the square-wave profile, the Skylab EVA profile, and the stress profile. Figure 10 is for subject $A$, also in the Apollo suit at the same conditions, exercising at the nominal ramp profile and the stress profile.

The results show the subjective comfort index, total body heat storage, controller-set LCG inlet temperature, LCG heat removal rate, evaporative heat loss rate, and tota! body heat stcrage rate. Convective heat loss was nearly negligible in all cases, and environmental heat loss through the suit was limited to negligible values by the use of the chamber heaters described previously.

Figures 9 (b) and 10 (b) show that subjective comfort remained in the comfort band ( 3 to 5) consistently except during brief transients when the controller was making rapid changes in inlet temperature following step changes to higher or lower work loads. These off-comfort periods represent mild overshoots and undershoots that were rapidly damped out. They are unavoidable because metabolic heat must pass through the skin and be percei ed as heat or cold before passing to the LCG and acting on the controller. This process entails a necessary lag time on the order of 2 to 3 minutes before the controller can resirand. However, during the nominal and Skylab profiles, the subjects never reported feeling hot or cold and only rarely did they report cool or warm sensations. During the stress profile, both subjects reported feeling hot for several minutes during or shortly after the maximum mctabolic rate spike of 1160 watts. Subject $B$ reported feeling warm for 3 minutes at the end of the 7.5-minute, 590-watt sequence of the stress profile and also for 4 minutes during the 15-minute, 590-watt period of the nominal squarewave profile. Both these periods represent activity levels that exceed the capacity of the LCG to provide comfort. Nonetheless, both subjects reported that cooling was acceptable because of the brevity of these off-comfort periods. Subject $A$ reported feeling cool on six occasions, none persisting longer than 1 to 2 minutes and each usually following a step change in work level, when the controller was in the process of making an adjustment. In conjunction witn this report, subject $A$ reported a preference for running cool as opposed to neutral, whereas subjert B o.eferred neutrality and mentioned only one brief cool period.

Figures $9: 0 j$ and $10(c)$ present the total body heat storage for these runs, calculated by the changes in rectal and mean weighted skin temperatures from their normal set values. Body heat storage is a particularly useful parameter because it quantitates individual variations in the subjective comfort index of different test subjects. These data show that at no tiine during any of the test periods did body heat storage approach or exceed NASA performance impaiment limits of +316.8 kilojoules

( +88 watt-hours) (ref. 2 ). In fact, heat storage values were almost a?ways commensurate with the comf ort levels associated with each metabolic rale. This result is encouraging in view of the fact that there were several deliberate off-comfort periods designed to stress the system.

Figures $9(d)$ and $10(d)$ show the contioller-set LCG inlet temperatures. It is observed that each inlet temperature profile is different and unique to each run. In general, the higher workloads caused the controller logic to respond with the lowest inlet temperatures and the ?ower workloads resulted in the highest inlet temperatures. However, on severa? occlasjons, 
this general rule was not the case because the controller and the LCG sensed an off-nominal physlological input and responded in a different manner. An exaple of this type of response occurred during the stress profile. For the Initial 33 minutes of this run, the controller did not drop the inlet temperature below $293 \times\left(20^{\circ} \mathrm{C}\right)$ despite the presence of two metabolic steps of 737 and 587 watts, lasting 10 and 7.5 minutes, respectively. The reason for this result is that the subject began the run with a reduced skin temperature and a body heat storage of $-108.0 \mathrm{k} 1$ lojoules ( -30 watt-hours). The controller did not attempt to iower the inlet temperature because the LCG $\Delta T$ was affected by the reduced sk in conductance. Consequent ly, the subject was kept comfortable throughout these stress work rates with a $T_{\text {in }}$ at or above $293 \times\left(20^{\circ} \mathrm{C}\right)$. However, as soon as heat storage increased and vasodilatation occurred, the controller responded to increased metabolic rates by dropping the inlet temperature. (At time $=35$ minutes, $T_{\text {in }}$ was dropped to $288 \mathrm{~K}\left(15^{\circ} \mathrm{C}\right)$.) This type action by the controller was observed on several occasions and demonstrates that the system can respond to important physiological mechanisms with a high degree of sensitivity.

One other point should be mentioned about the inlet temperature profiles. The controller logic was fine-tuned during the initial tests to optimize the response time and performance. This procedure consisted of adjusting the gain constants before, but not during, each test until the best response was achieved. Consequently, the inlet temperature profiles show are not the result of the identical controller logic. Of the results shown, only the Skylab EVA profile represents the response of the final optimized control logic. The changes that were made in the control logic are sumnarized in the discussion.

Figures $9(e), 9(f), 10(e)$, and $10(f)$ show the LCG heat removal and total evaporative heat removal for each test. The LCG heat removal varies inversely with the controller-set LCG inlet temperature (LCG heat removal $=$ flow rate $\times$ LCG $\Delta T$ ) and is greater than the evaporative heat loss. If the controller is to work, it must vary the LCG heat removal such that the evaporative heat loss is imited to a nearly constant value (ref. 2). In this way, sweat rates are kept below disconf ort 1 imits of $100 \mathrm{~g} / \mathrm{hr}$ (ref. 9) but are not eliminated entirely; complete cessation can also cause discomfort. The results show evaporative heat loss never exceeding 90 watts (except briefly during one stress period at a metabolic rate of 1160 watts) and remaining relatively constant during each test run. These heat loss rates correspond to active sweat rates well below $100 \mathrm{~g} / \mathrm{hr}$ and demonstrate the effectiveness of the controller logic in regulating LCG heat removal to limit, but not eliminate, sweat rates to comfort values.

Figures $9(g)$ and $10(g)$ present the total body heat storage rate for each run, as calculated from the total body heat balance equation. This term represents the difference between the heat produced by metabolism and the total heat removal from the subject (LCG + convection + total evaporation + mechanical work). It also represents the instantaneous direction of heat storage - into (positive) or out of (negative) the body - and, as such, is useful in assessing the lag time between the production of heat and its removal. If the controller operates properly, the time integral of heat storage rate should approach zero; the changes in the slope (positive to negative or vice versa) of the rate should be frequent and the absolute value of the storage rate should only instantaneously approach 
and never exceed the magnitude of the corresponding metabolic rate. An ideal controller would maintain a near-zero storage rate at all times. However, because of thermal lag times, a real controller must operate by undershoots and overshoots. Therefore, the more frequent the changes and the lower the magnitude of the values, the better the controller. These results show the slope of the heat storage rates changing sign on the order of every 10 minutes or less, a change indicating frequent controller responses, with the magnitude of the storage rate well below the corresponding metabolic rate. Most important, the time integral of the rate approaches zero and does so fairly rapidiy after the onset of work. On the basis of these data, the response of the controller is quite acceptable. Furthermore, it will be significantly improved when a constantly responding closed-loop system is developed to replace the discrete, digital method used in this feasibility study.

\section{Controller Use Compared With No Control}

Figures 11 and 12 present the results for runs in which the subjects exercised at the same metabolic profile with and without the controller operating. Figure 11 presents the data for a nominal square-wave profile with the controller operating compared with the case of a constant $T_{\text {in }}$ of $300 \mathrm{~K}\left(27^{\circ} \mathrm{C}\right)$, which corresponds to the inlet temperature requested for comfort at rest. Figure $11(b)$ shows that with no controller, subjective comfort could not be maintained during either of the high-workload periods. However, with the controller, comfort was maintained throughout except for one brief period in the middle of the first high-workload rate, which again resulted from the lag time required for the LCG to sense the additional metabolic heat and for the controller to respond to it.

Figure $11(c)$ shows that body heat storage reached significantly higher levels without the controller $(216.0$ kilojoules (60 watt-hours) compared to $108.0 \mathrm{kilojoules}$ ( 30 watt-hours)). In fact, fol lowing the constant-temperature run, the subject had so much trapped sweat in the A7LB suit, because of this high heat storaje, that the resulting evaporative heat loss during the ensuing rest period overcooled him before the next run. This effect did not occur when the controller was used, as the data in figure $12(\mathrm{c})$ indicate. Here, for the constant-temperature run, the evaporation heat loss (which represerits sweating) reached 102 watts within 20 minutes of the start of the run and remained high thereafter (corresponding to a saturated-suit out let dewpoint). Conversely, with the controlier operating, evaporative heat loss never exceeded 75 watts.

Figure 12 shows the results for similar comparison runs for a different subject, with the use of a cooler constant $T_{\text {in }}$ of $294 \mathrm{~K} i 21^{\circ} \mathrm{C}$ ), which corresponds to the temperature requested for comfort at a metabolic rate equal to the average rate for the run ( 300 watts). In this case, using a colder fixed $T_{\text {in }}$ resulted in excessively long subjective cold response and rapidly changing impressions of subjective comfort from cold to warm and vice versa (fig. 12(b)). This result is contrasted with the rather steady comfo:t reports obtained with use of the controller, punctuated by three brief 3- to 4-minute periods of cool repurts immediately following controller response to a step change in workload. (It should be added that the test subject in this case reported a preference to "run cool.") 
The rest of the data in flgure 12 show only small differences in the heat storage and sweat rates for most of the two runs because the constant $T_{\text {in }}$ of $294 \mathrm{~K}\left(21^{\circ} \mathrm{C}\right)$ is capable of preventing wide swings in heat storage and sweating for this particular moderate metabolic rate profile. However, for the last 20 minutes of the constant-temperature case, the sweat rate and heat storage increased markedly in response to the high-workload ramp. whereas they remained fairly constant during automatic control.

The previous data show the advantage of using an automatic control system to regulate LCG inlet temperature as opposed to a single set temperature that would be acceptable for some metabolic rates but unacceptable for others.

\section{Automatic Control Compared With Manual Control}

Figure 13 presents the results from the Skylab EVA profile run with the subject manually regulating the $T_{1 n}$ according to his own comfort, as contrasted with the same run under automatic control. Although the metabolic rates (fig. 13(a)) experienced during the actual EVA were higher than those experienced on most other missions, they are representative of peak workloads and durations that could be expected for space construction tasks.

Figure 13(b) shows that there was no significant difference between the subjective comfort reports by the astronaut test subject for the two cases. In other words, the controller provided the same level of subjective comfort to the subject as he could manually provide himself.

Figure $13(\mathrm{c})$ shows the total body heat storage for both cases. As might be expected, both runs showed low values of body heat storage that were close to the steady-state comfort band and well within the performance impairment 1 imits of +316.8 kilojoules ( +88 watt-hours). It should be noted that for the manual control case, body heat storage started and finished with negative values, a result indicating a desire on the part of the subject to overcool himself in anticipation of high metabolic rates.

Figure $13(d)$ presents a comparison between the manually selected inlet temperature and the automatically controlled inlet temperature. Here, it can be seen that the controller logic selected almost the identical inlet temperature profile as the subject selected for himself. The only differences that occurred resulted from the fact that the controller adjusted the in let temperature in direct response to the workload and did not overcool the subject at the lower work rates as he himself did under manual control between 40 and 50 minutes into the run and, again, between 73 and 87 minutes.

Figure 13(d) also indicates that, when the LCG cooling was under manual control, the subject made 11 cooling-valve changes (indicated by arrows) in 9 : minutes of testing. This change frequency represents a significant amount of time spent attending to cooling adjustments that would be better spent on work tasks if automatic cooling control were available. Furthermore, it was observed that astronauts did not make manual adjustments during actual EVA's with the frequency that was observed during this run. The conclusion here is that work tasks cause the crewman to ignore his thermal 
status, and tnereby there is a resultant possibility of heat storage, fatigue, or work inefficiency problems.

Figures $13(\mathrm{e})$ to (g) present other physiological data comparing the ini.iual and automatic runs. Again, no significant differences were observed je: :ween the two types of runs with respect to LCG heat removal rates, s. eat evaporation rates, and body heat storage rates. All results indi( ited thermal comfort, a consequence emphasizing the potential for this :.ype of controller to equal and possibly exceed the performance of a manwal control system.

\section{Effect of Other Parameters Examined}

In addition to the test factors discussed previously, there were (i: her parameters examined in this feasibility study, including the effect $c:$ heat loss to the environment, the effect of different water flow rates, the effect of test subject variability, the repeatability of test results, and the effect of different suits or covering garments. Although the results are too detailed to be presented in their entirety in this report, they may be summarized as follows.

1. Environmental heat loss did not noticeably affect the ability of the controller to provide thermal comfort within the range of 0 to 75 watts of heat loss out of the suit. It is anticipated that for heat losses (or gains) of greater magnitude, a manual bias would be required to provide adequate performance. This bias would anount to a shifting of the intercepts (either up or down) without a change in slope of the curves of figures 2 and 3 .

2. Runn ing the LCG at a lower flow rate $(55 \mathrm{l} / \mathrm{hr})$ makes it more difficult $f_{\text {.. }}$ the controller to operate because the changes in LCG $\Delta T$ are much larger and occur faster. Although controller performance at the lower flow rate was acceptable, the instabilities that occurred would probably limit the usefulness of this type of controller logic to flow rates no lower than $55 \mathrm{l} / \mathrm{hr}$.

3. No significant difference was noted in controller performance amons the three test subjects, despite the fact that one was an astronaut in excellent "ysical condition, another was a male, and the third was a female of zonsiderably smaller size. The physiological (other than heart rate) er.t hermal-comfort data recorded showed no statistically significant trends wat could be attributed to subject variability.

4. The controller performance was repeatable under identical test -unditions. Several duplicate runs made with the same controller logic yielded similar results.

5. The use of different types of suits covering the LiG has the effect of (a) varying the metabolic rate required to perform the same work task and (b) affecting the net environmental heat exchange between the subject and his environment. The three types of covering suits tested were t'ie Apollo A7LB space suit, an arctic (goose down) garment, and a plain pair of coveralls. Use of the Apollo suit necessitated alinost 50 percent 
more matabolic effort to walk at the sune treadnill speed used in the test involving the coveralls. However, the coveralls did not insulate the LCG from the environment and thereby caused a deceptively lower LCG ST at the same metabolic rate and more sluggish controller performance.

If the controller were used with an LCG for ground applications, the sensitivity of the logic would have to be increased by augmenting the gain constants appropriately.

\section{DISCUSSION}

The results of this study conclusively demonstrated the feasibility of a controller that can maintain human themal confort by measuring LCG $\Delta T$ and inlet water temperature alone. The three primary criteria used to assess the success of the controller concept were tot al body heat storage, subjective comments by the test subjects, and sweat rates. These results are sumarized fo: all controller runs in figures 14 to 16.

Figure 14 presents the extremes in total body heat storage for each test. It can be seen that the maximum and minimum values for each test never approached the performance impairment limits of +316.8 kilojoules ( +88 watt-hours) and very rarely deviated from values associated with comfort.

Figure 15 presents typical subjective comfort index results for four tests, two with and two without the controller. Here, it is seen that with the controller, subjective confort was confined to the comfort zone except for brief transient periods, whereas without the controller, deviations were much larger and more frequent.

Finally, figure 16 presents the extremes in evaporative heat removal (sweat rate + respiration loss + skin diffusion) for each test. It can be seen that maximum total water loss was limited to below $160 \mathrm{~g} / \mathrm{hr}$ for all controller tests, a value associated with light sweating and confort (ref. 2). This result is contrasted with evaporative losses greater than $185 \mathrm{~g} / \mathrm{hr}$ (equivalent to moderate-to-heavy sweating) at a constant $T_{\text {in }}$ of $299 \mathrm{~K}\left(26^{\circ} \mathrm{C}\right)$. In other words, the controller acted to limit and prevent heavy sweating associated with discomfort but, at the same time, did not overcool the subject ty reducing sweat rates below minimal values necessary for comfort at low metabolic rates.

During the course of these tests, two primary adjustments in controller logic were made. It was found that the initial 50-50 split between the steady-state and the transient contribution to the $T_{\text {in }}$ calculation was tou unstable. Consequently, the gain constants were shifted to an 80-20 dependence favoring the steady-state contribution. This shift was determined by a trial-and-error process and represented the only real deviation from the theoretical values derived in the pretest 4l-Node Man simulation runs.

The only other adjustment was to increase the sensitivity of the controller for LCG inlet temperatures greater than $298 \mathrm{~K}\left(25^{\circ} \mathrm{C}\right)$. This 
change consisted of doubling the gain constants for the transient contribution to the $T_{i n}$ calculation. The reason for this change was to account for a reduced heat transfer coefficient of the LCG at the higher inlet temperatures, a factor that had been overlooked. This reduced LCG effectiveness at high inlet temperatures has been observed in the past (ref. 2) and is thought to result from reduced sweat pathways between the LCG tubes at lower metabolic rates, which reduce the effective LCG-to-skin conductance. This effect makes it more difficult for the LCG $\Delta T$ to respond to higher metabolic rates, a condition that was countered by increasing the controller sensitivity to a change in LCG $\Lambda T$.

\section{CONCLUDING REMARKS}

This feasibility study has shown that an automatic controller, responding only to changes in inlet temperature $\left(T_{i n}\right)$ of a liquid-cooled garment ( $L C G)$, can maintain therrial balance in persons working at a wide range of metabolic rates. Subjective comments from the test subjects also verified the capability of the controller to maintain comfortable conditions under all reasonable workloads. The results of this study can be used as guidelines for development of a prototype automatic controller unit.

The actual hardware should consist of a water-mixing valve coupled to a servomotor and a microprocessor "chip" that contains the controller logic. The microprocessor would continuously sample measurements of LCG $T_{\text {in }}$ and the temperature difference between LCG inlet and out let water, would compute a new desired $T_{i n}$, and would initiate a signal to the servomotor, which in turn would change the position of the water-mixing valve to get the desired $T_{\text {in }}$.

The lag time associated with this controller should be designed to filter out system fluctuations. This lag time, as well as the controller gain constants themselves, depends upon the type of system used and its applications. For the Space Shuttle extravehicular mobility unit, the portable life-support-system lag time will be approximately 30 seconds. The data from these tests indicate that the differential and integral terms in the transient term of the logic play a minor role in the determination of a desired $T_{\text {in }}$ and can probably be ignored. Therefore, the inicroprocessor would be extremely simple, using only two linear curves as the basis of the analog circuit. The resulting chip should be relatively inexpensive to build and extremely small and light.

However, for other applications, the gain constants and lag times may be different, a factor leading to microcircuitry of varying complexity. Ground use of the controller in a shirt-s leeve environment, for example, would necessitate increased sensitivity of the logic, because ordinary clothing does not insulate the LCG.

Lyndon B. Johnson Space Center National Aeronautics and Space Administration Houston, Texas, July 29, 1977 $986-00-15-00-72$ 


\section{REFERENCES}

1. Webb, P.: Metabolic Heat Balance Data for 24-Hour Periods. Int. J. Blometeorol., vol. 15, Dec. 1971, pp. 151-155.

2. Kuznetz, Lawrence H.: Control of Thermal Balance by a Liquid Circulating Garment Based on a Mathematical Representation of the Human Thermoregulatory System. MASA TM X-58190, 1976.

3. Waligora, J. M.; Hawkins, W. R.; et al.: Apollo Experience Report Assessment of Metaboilc Expenditures. MASA TN D-7883, 1975.

4. Nu:,nely, Sarah A.: Water Cooled Garments: A Review. Space Life Sci., vol. 2, Dec. 1970, Pp, 335-360.

5. Chambers, Alan B.; and Blackaby, James R.: A Liquid-Cooled Garment Temperature Controller Based on Sweat Rate. Second Conference on Portable Life-Support Systems, NASA SP-302, 1972, pp. 283-287.

6. Webb, Paul: Automatic Cooling: Strategies, Designs, and Evaluations. Portable Life Support Systems. NASA SP-234, 1970, pp. 159-170.

7. Morgan, L.; Collett, G.; and Cook, D.: Computer Program Documentation for 41-Mode Transient Metabolic Man Progran. LEC/672-23-03003, Lockheed Electronics Co., 1974.

8. Stolwijk, J. A. J.; and Hardy, J. D.: Temperature Regulation in Man A Theoretical Study. Pflugers Archiv., vol. 291, Sept. 1966, pp. 129-162.

9. Webb, Paul; and Annis, James: Cooling Required to Suppress Sweating During Work. J. Appl. Physiol., vol. 25, no. 5, 1968, pp. 489-493.

10. Waligora, Janes M.; and Michel, Edward L.: Application of Conductive Cooling for Working Men in a Thermally Isolated Environment.

Aerosp. Med., vol. 39, no. 5, 1968, pp. 485-487. 


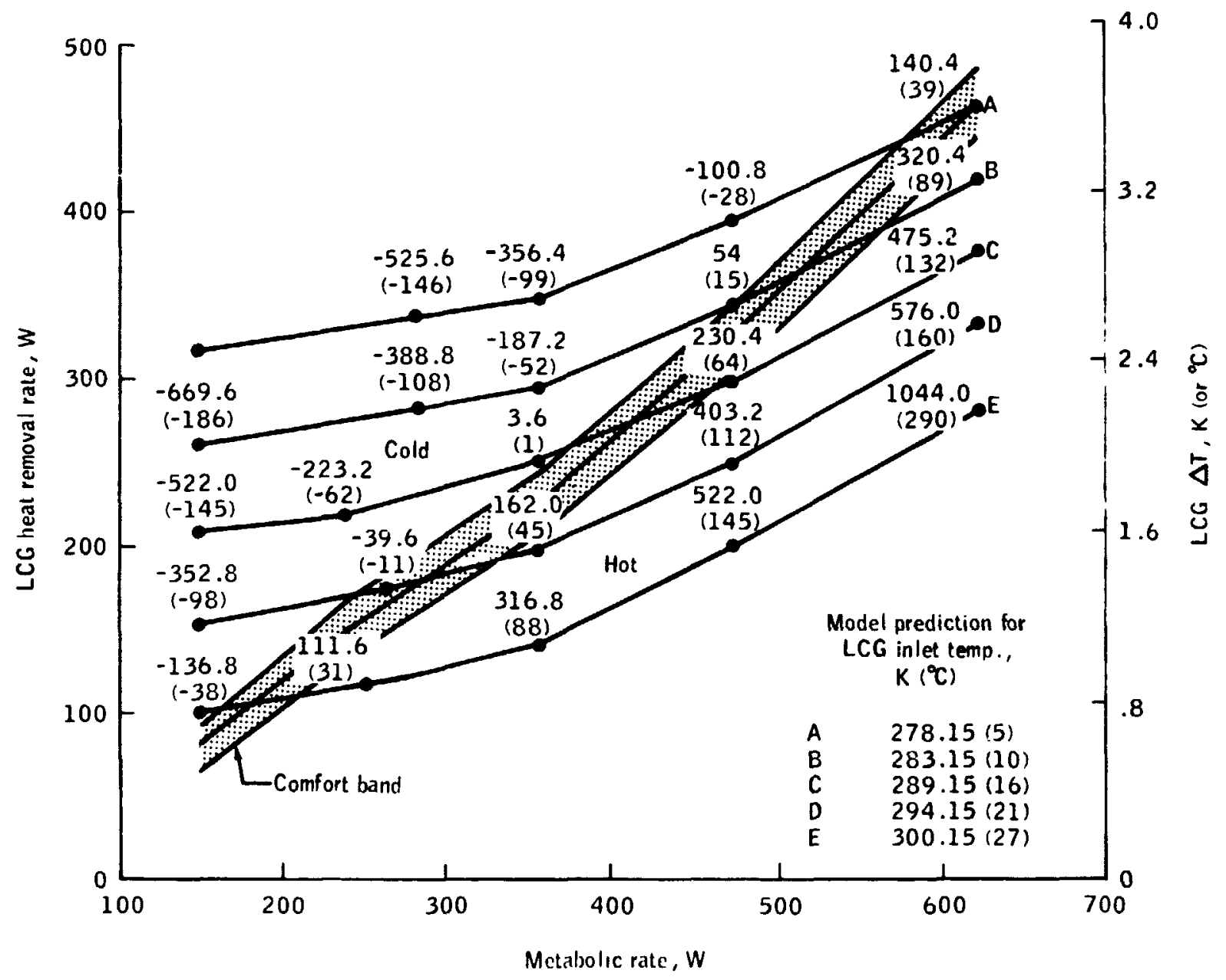

Figure 1.- Prediction of LCG heat removal (or LCG $\triangle T$ ) as a function of metabolic rate. The numbers adjacent to the lines of constant LCG inlet temperature represent total body heat storage predictions, in kilojoules (watt-hours), at metabolic rates of $146,234,352,469$, and 586 watts. 


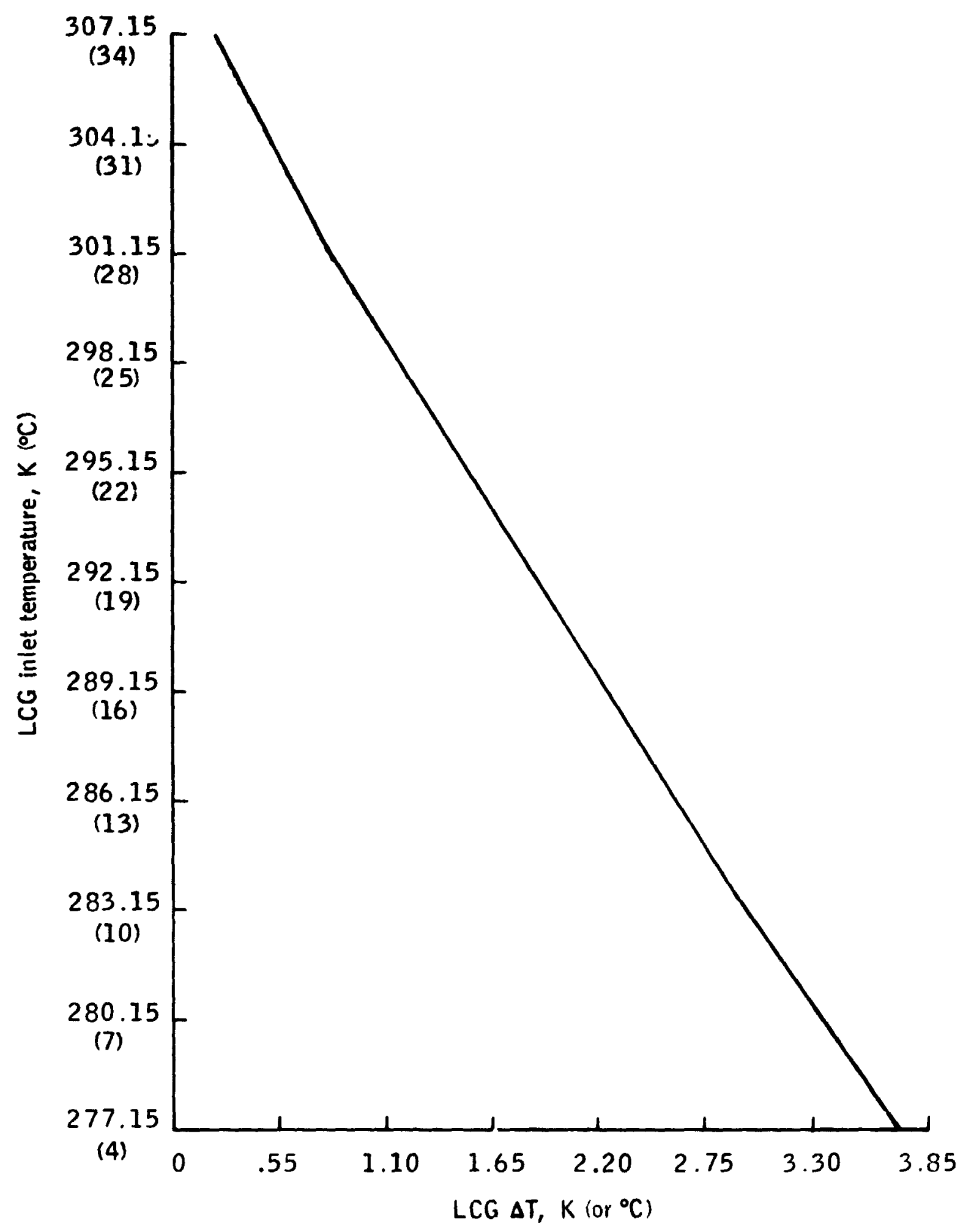

Figure 2.- LCG inlet temperature in relationship to LCG $\triangle T$ at the comfort level. 


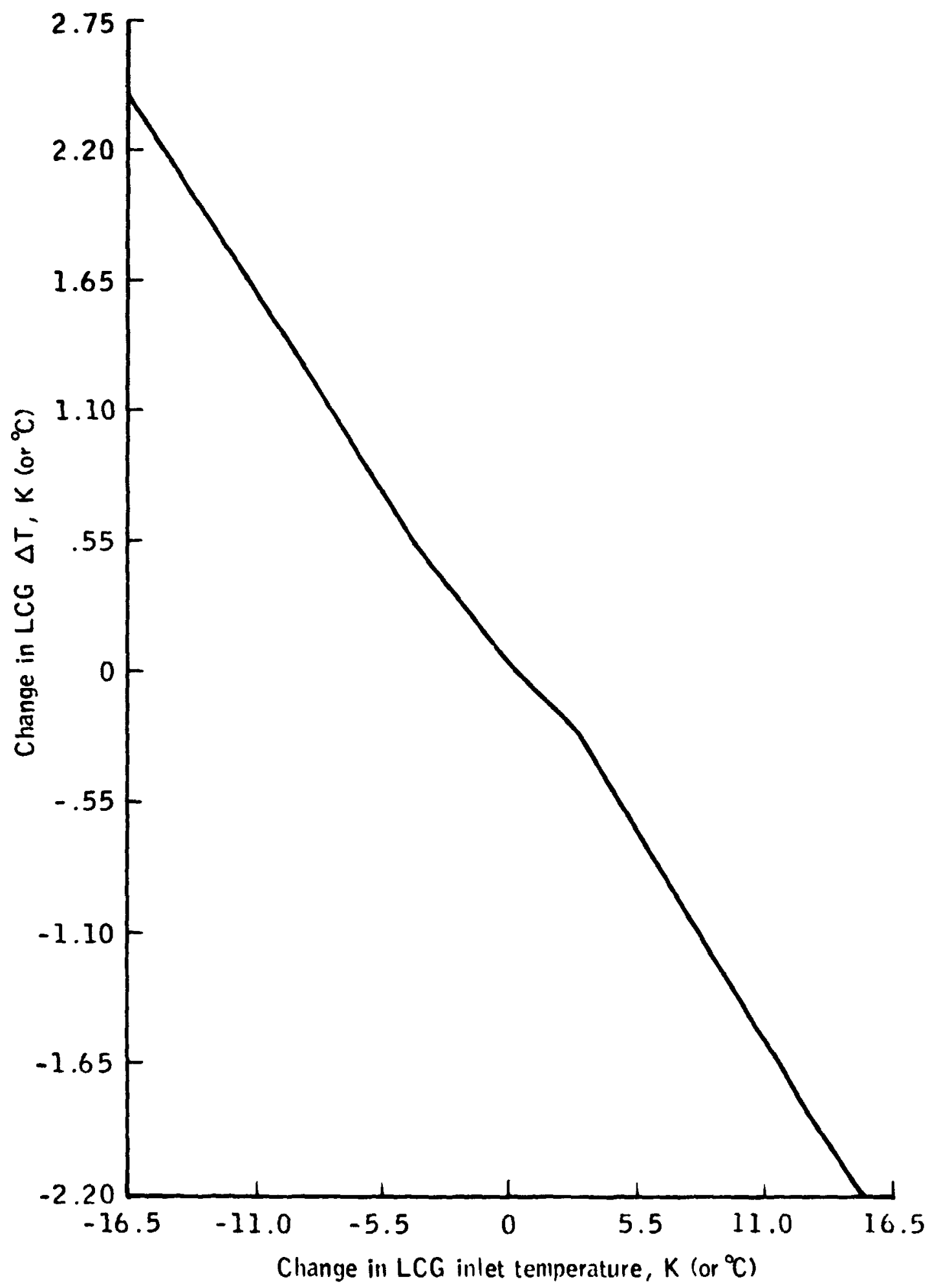

Figure 3.- Change in LCG $\triangle T$ compared to change in LCG inlet temperature while comfort is tracked. 


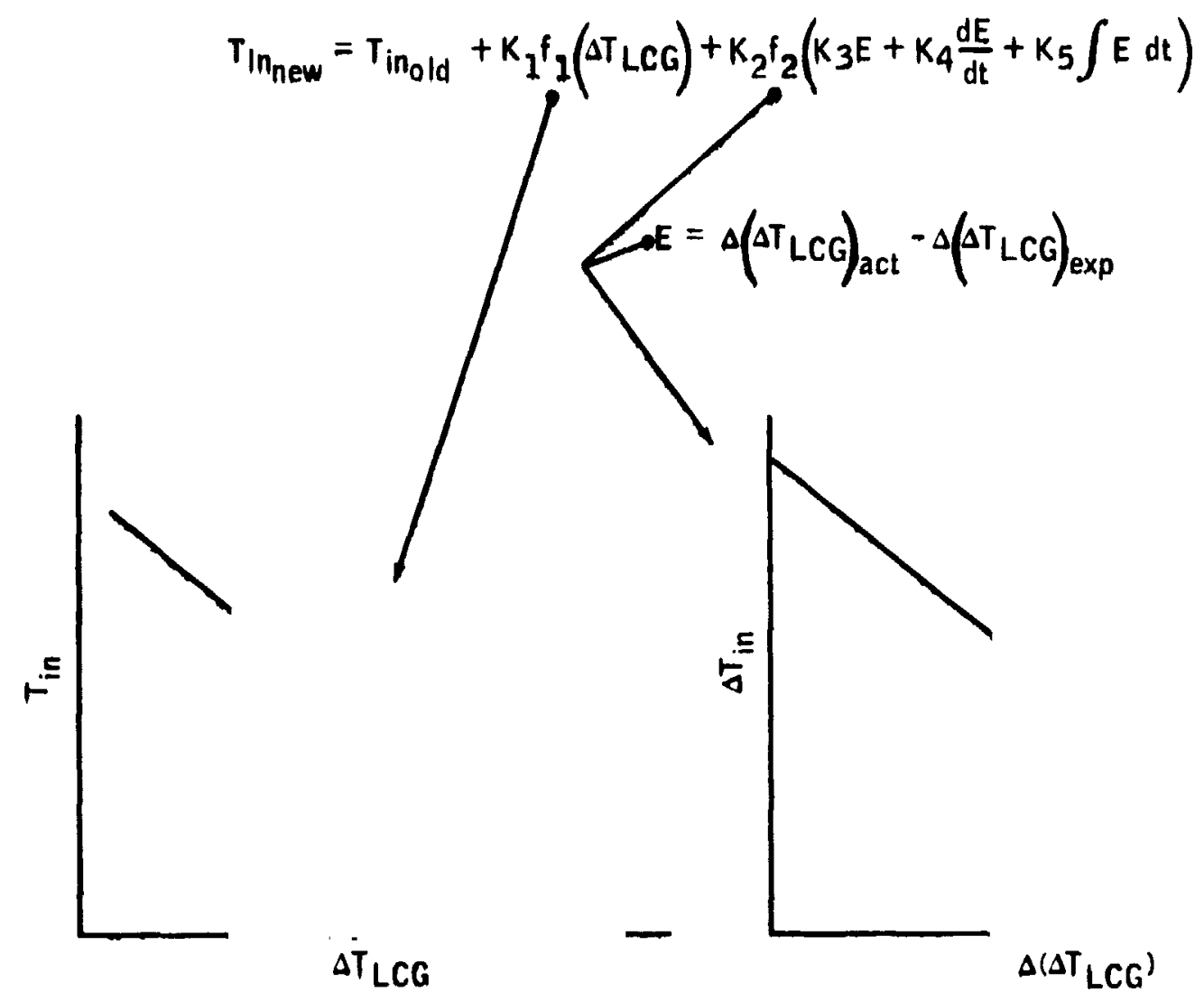

Figure 4.- Equation derived for controller logic.

20 

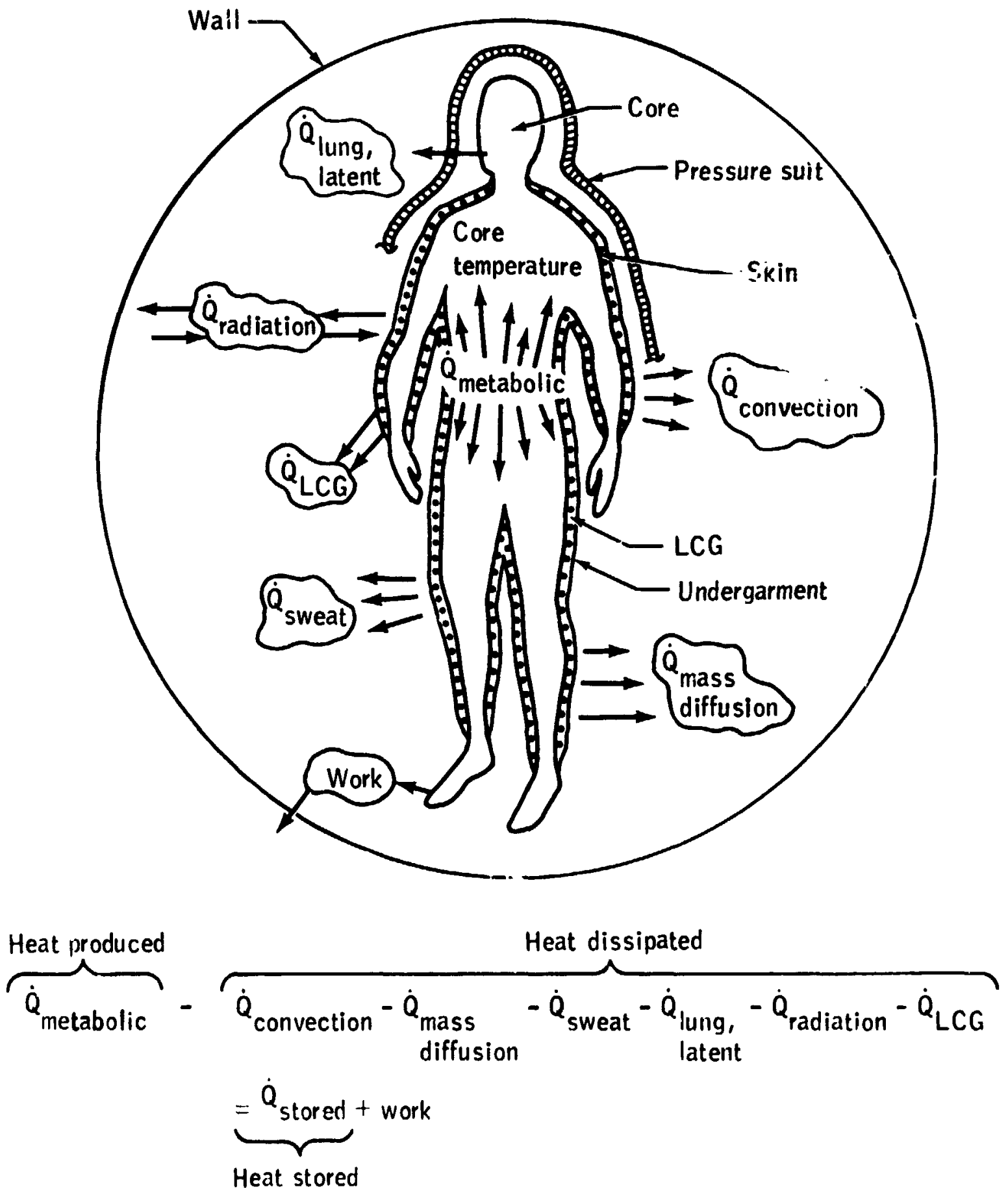

Figure 5.- Total body heat balance equation, where $\dot{\eta}$ indicates heat. 


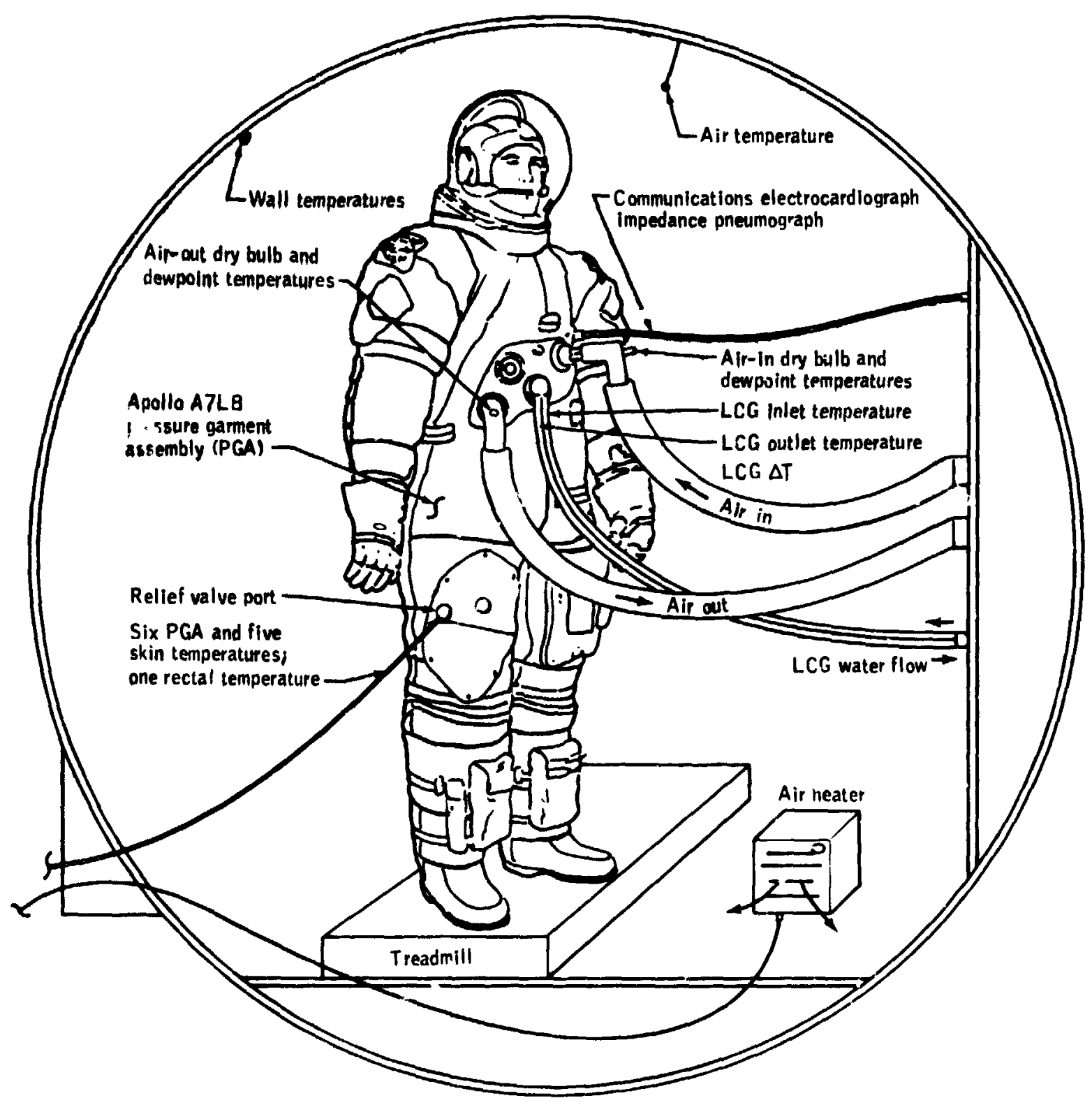

Figure 6.- Test subject and instrumertation for measuremtints. 


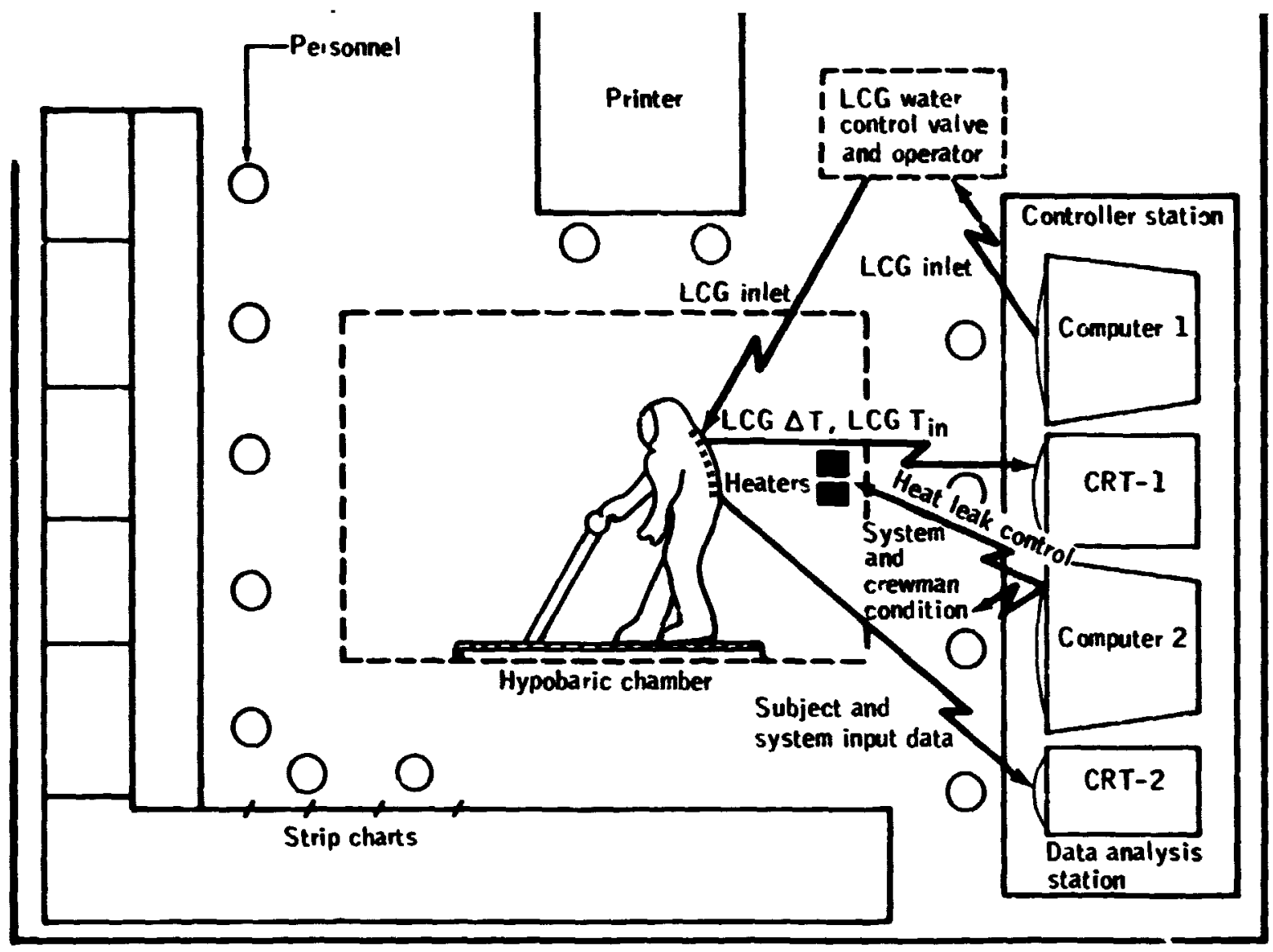

Figure 7.- Operational layout of the test control room.
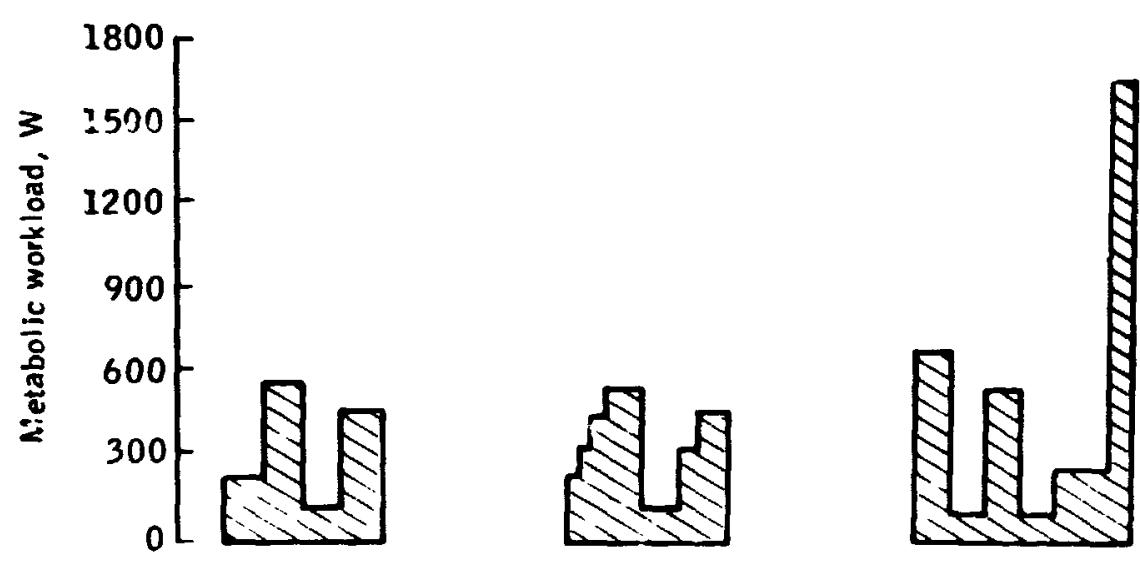
(a) Step.
(b) Ramp.
(c) Stress.
(d) Skylab.

Figure 8.- Patterns ${ }^{\circ}$ " Tetabolic rate profiles over time. 


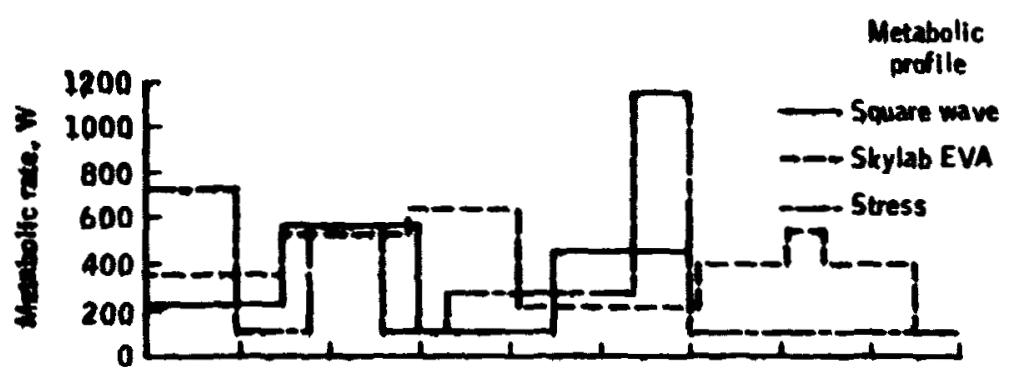

(a) Metabolic rate.

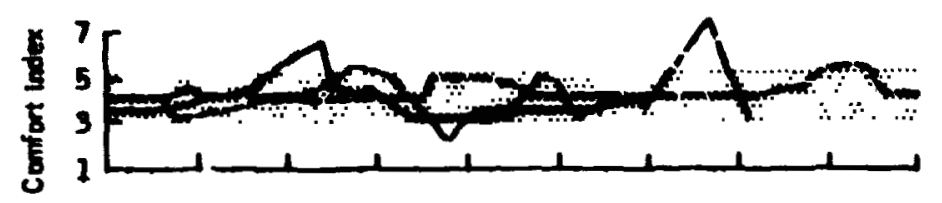

(b) Comfort index with comfort zone shaded,

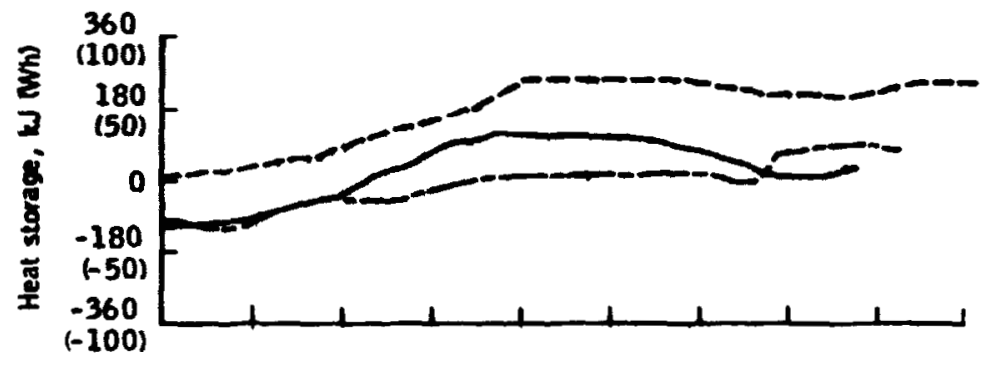

(c) Total body heat storage.

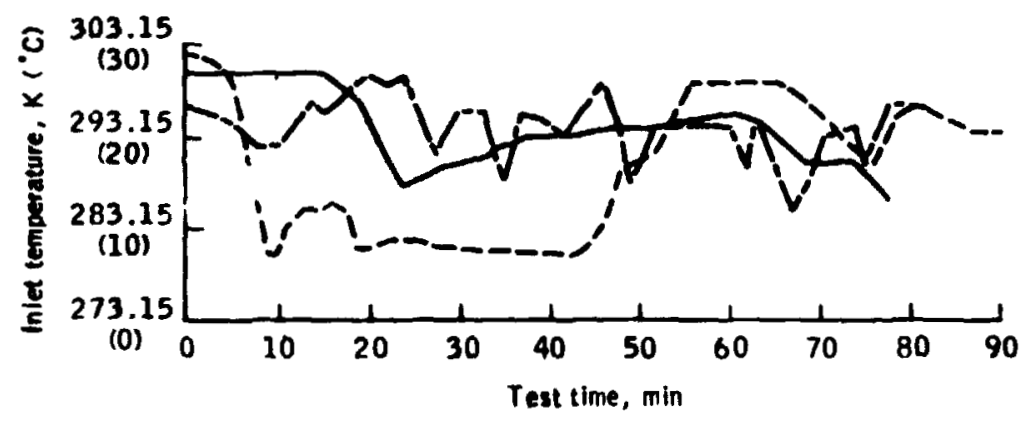

(d) LCG inlet temperature.

Figure 9.- Performance of automatic controller (with LCG under space suit worn by subject $B$ ) for three metabolic profiles. 


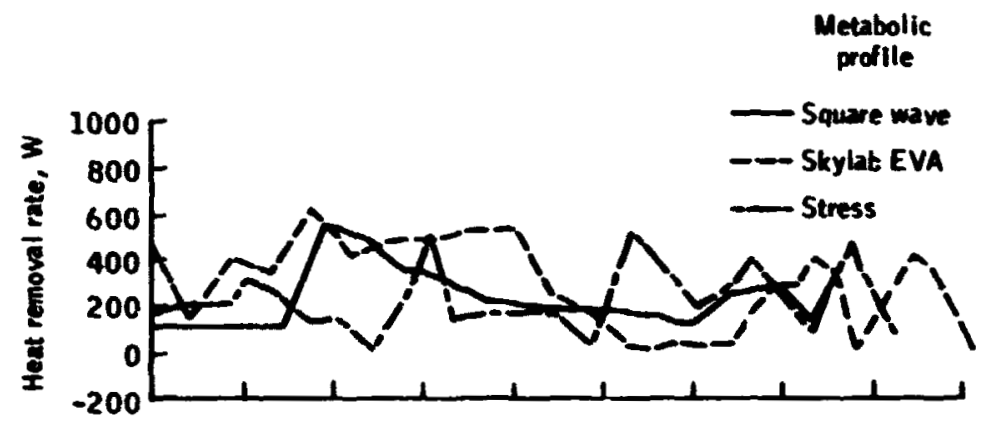

(e) LCG heat removal rate.

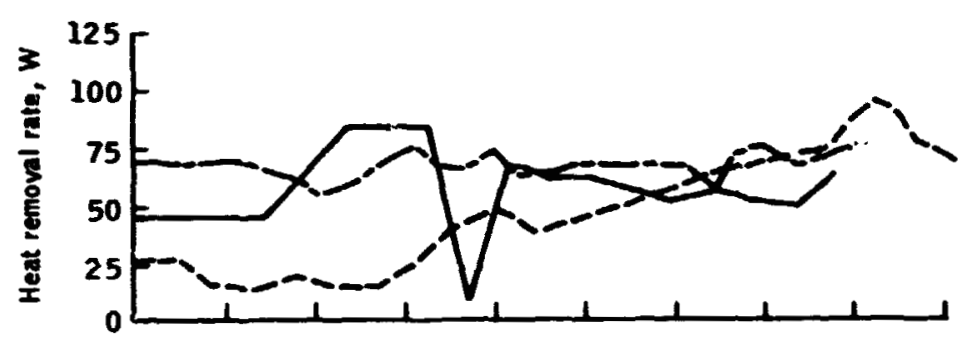

(f) Evaporative heat removal rate.

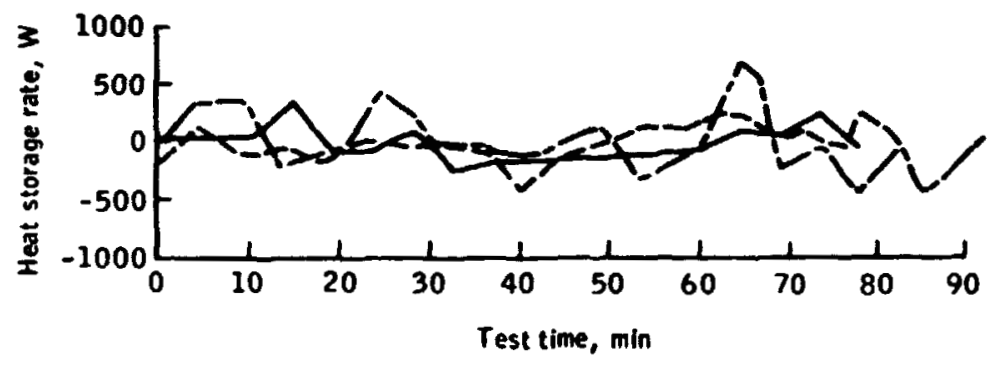

(g) Body heat storage rate.

Figure 9. - Concluded. 


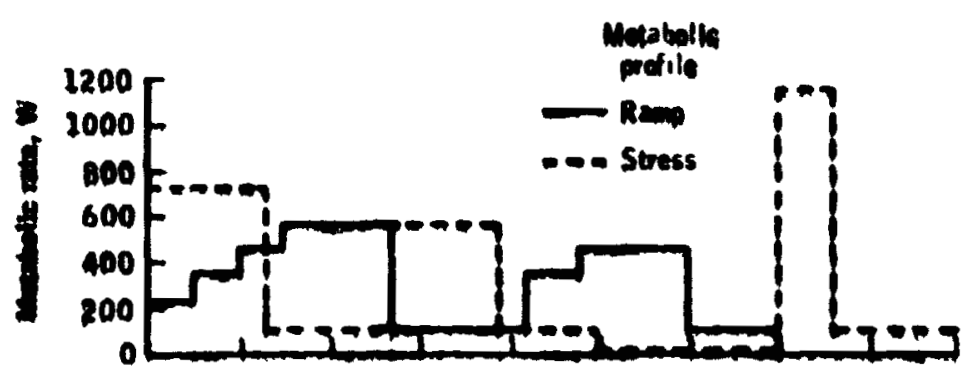

(a) Motabolic rate.

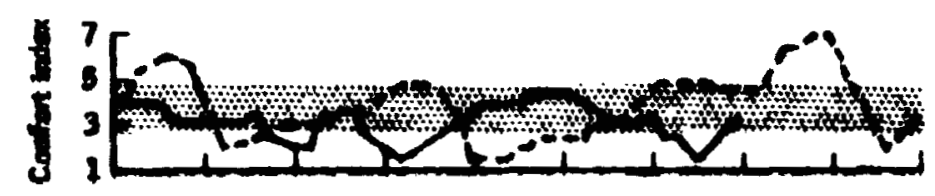

(b) Comfort index with comfort zone shaded.

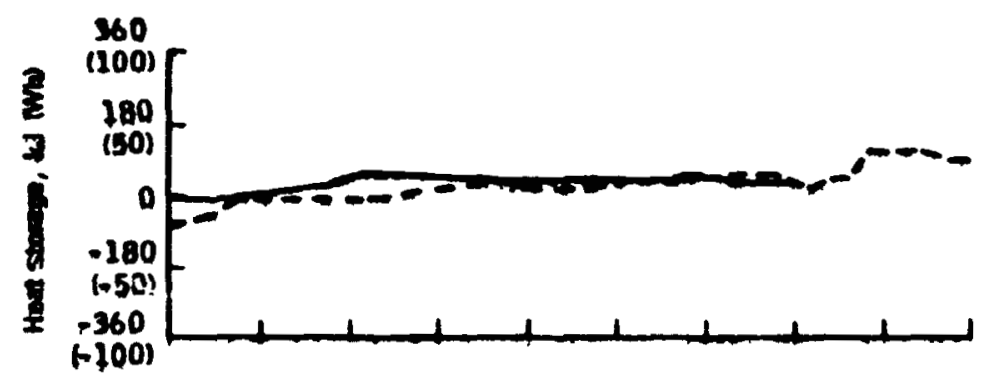

(c) Total body heat storage.

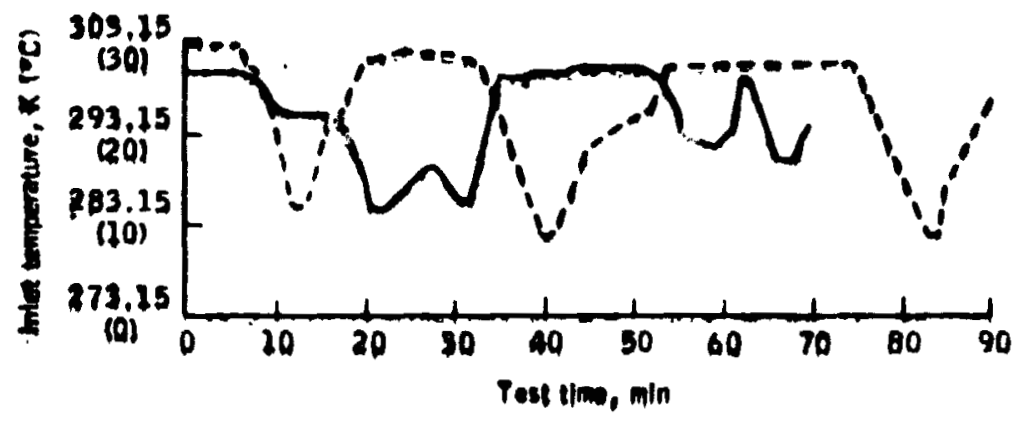

(d) LCG Inlet temperature.

Figure 10.- Performance of automatic controller (with LCG under space suit worn by subject $A$ ) for two metabolic profiles. 


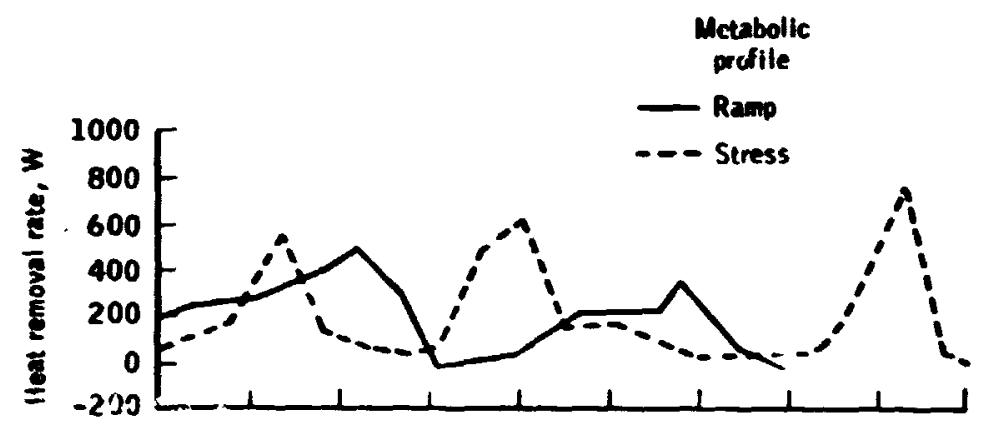

(e) LCG heat removal rate.

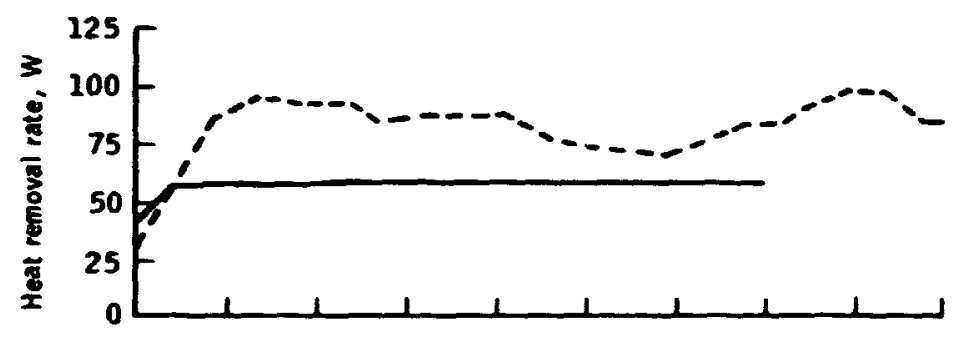

(f) Evaporative heat removal rate.

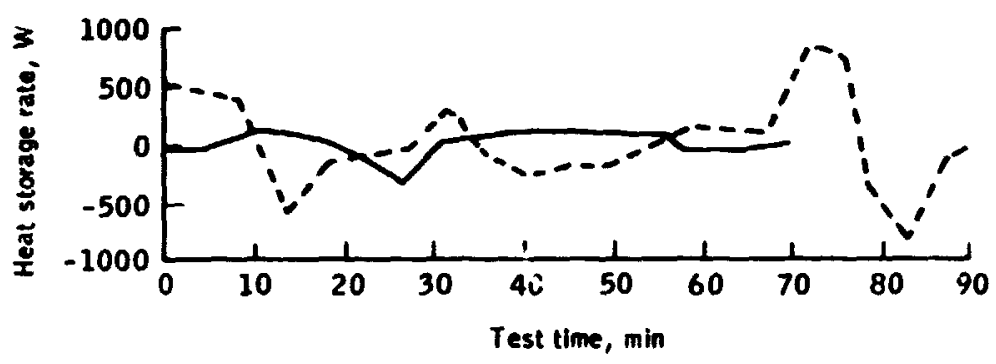

(g) Body heat storage rate.

Figure 10.- Concluded. 


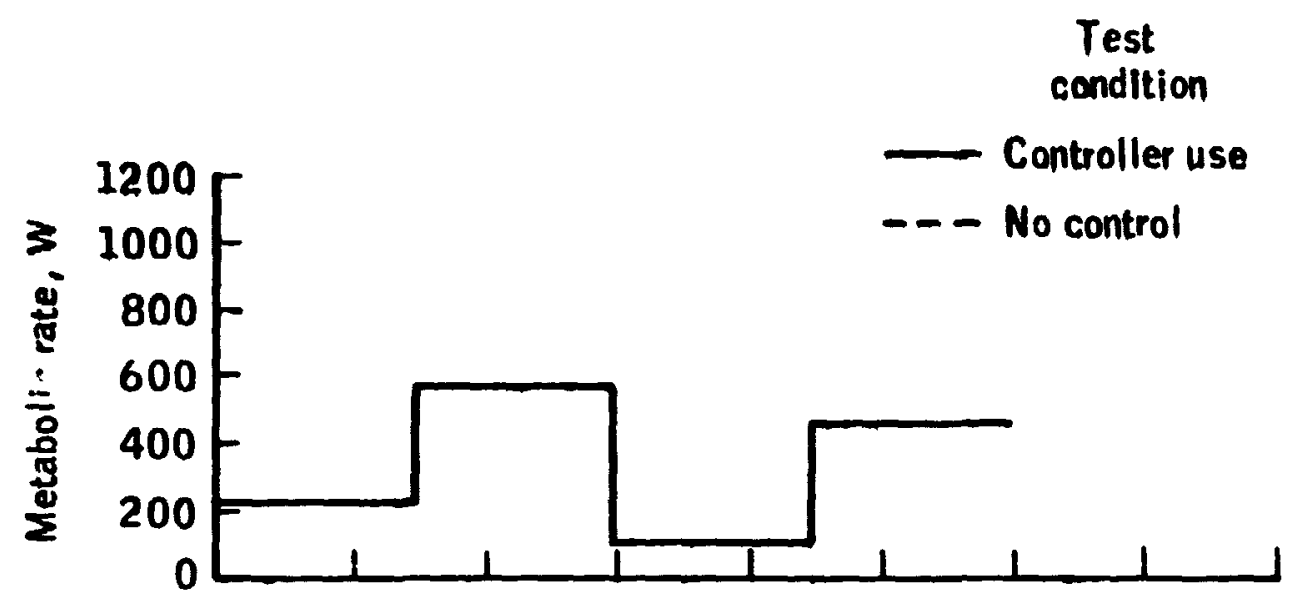

(a) Metabolic rate.

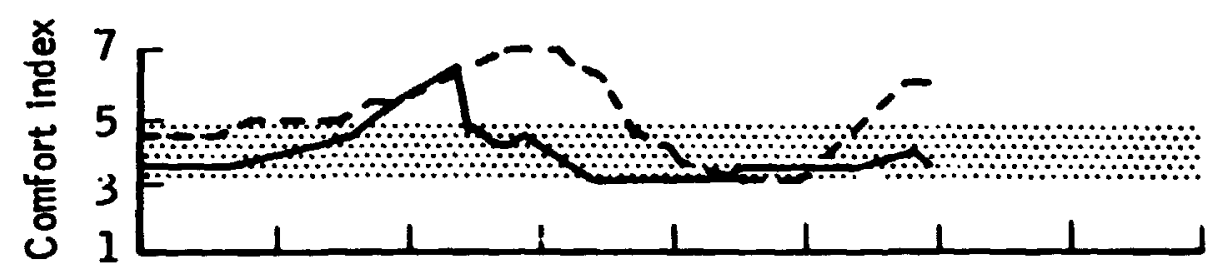

(b) Comfort index with comfort zone shaded.

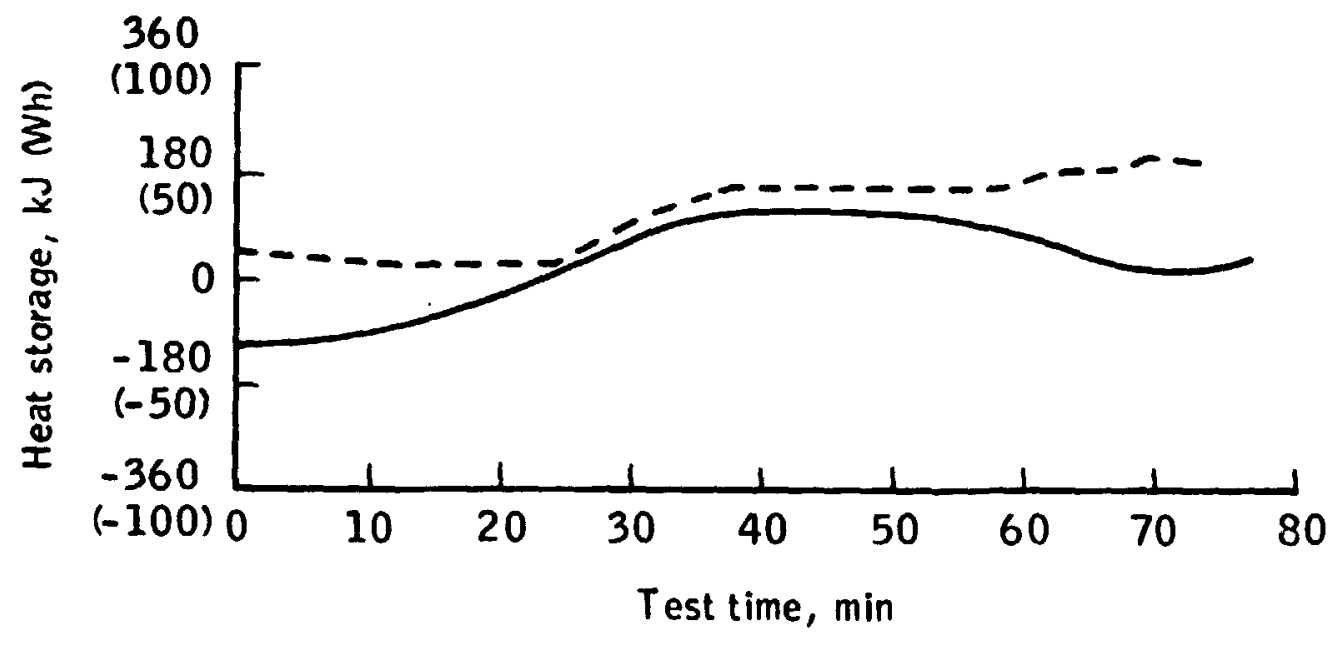

(c) Total body heat storage.

Figure 11. - Automatic controller performance compared with no control (at a constant inlet temperature of $300 \mathrm{~K}\left(27^{\circ} \mathrm{C}\right)$ ) during test runs by subject $\mathrm{B}$ at a nominal square-wave profile. 
Tesi condition

- Controller use

- - No control

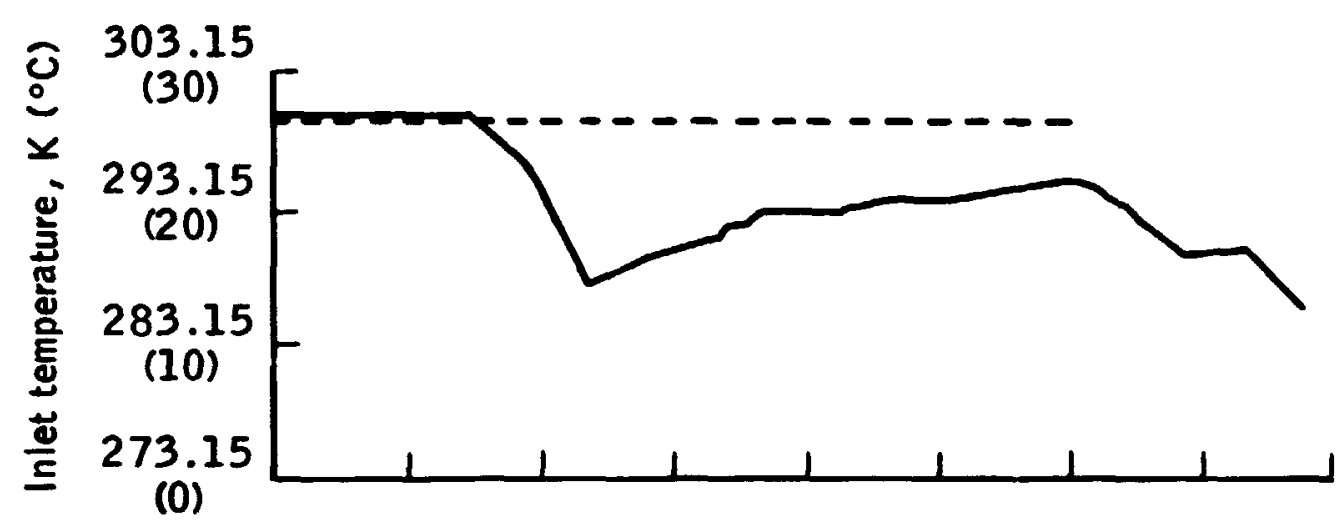

(d) LCG inlet temperature.

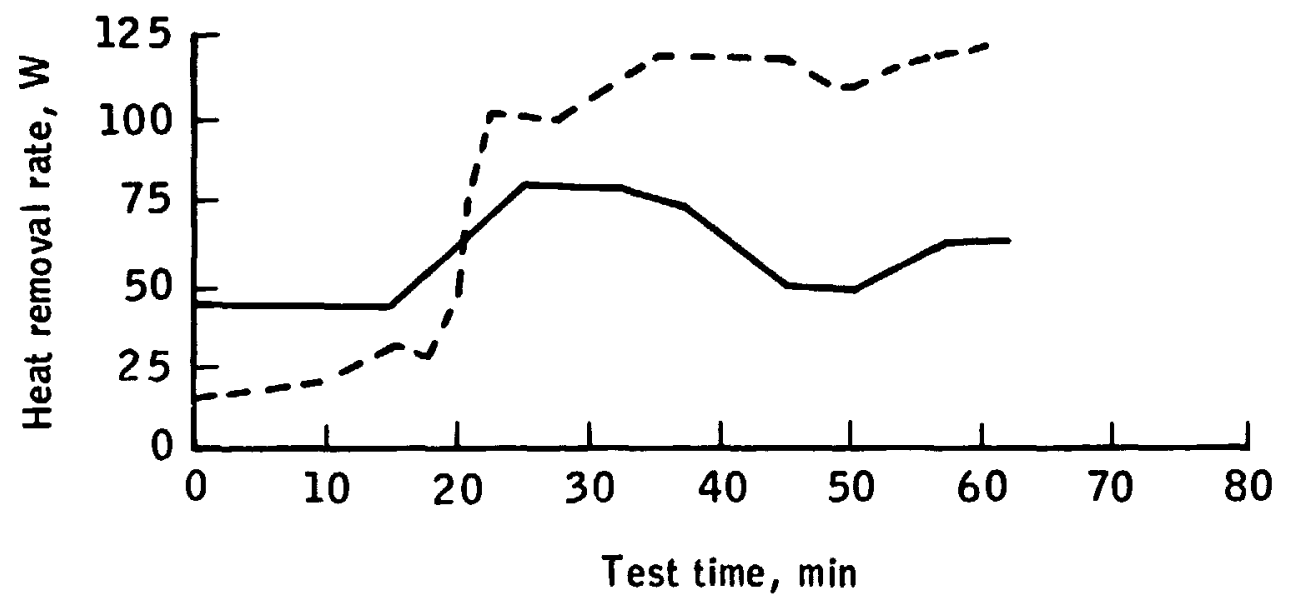

(e) Evaporative heat removal rate.

Figure 11.- Concluded. 


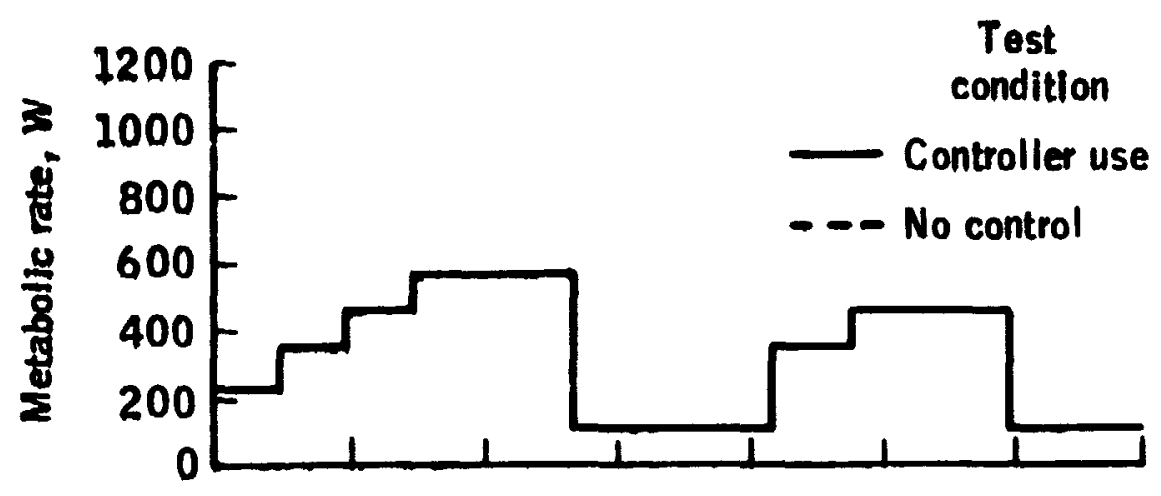

(a) Metabolic rate.

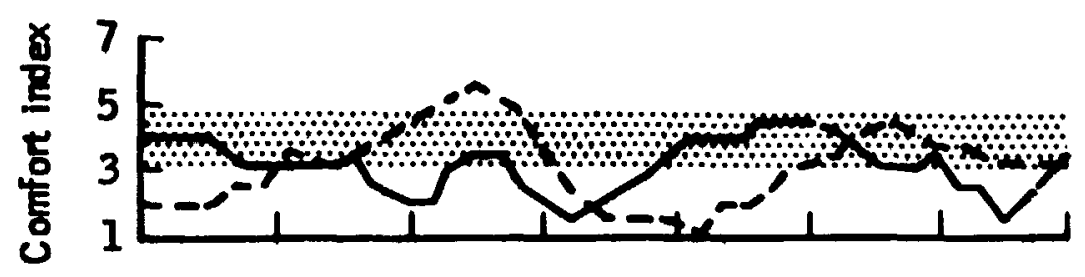

(b) Comfort index with comfort zone shaded.

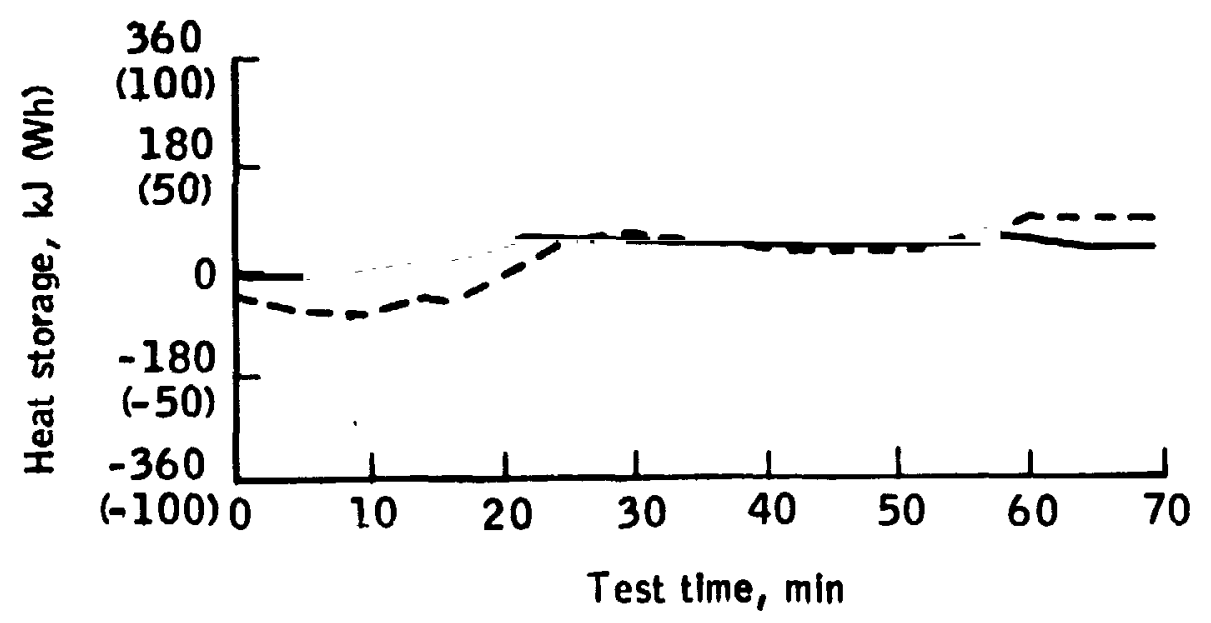

(c) Total body heat storage.

Figure 12.- Automatic controller performance compared with no control (at a constant inlet temperature of $294 \mathrm{~K}\left(21^{\circ} \mathrm{C}\right)$ ) during test runs by subject $A$ at a nominal square-wave profile. 


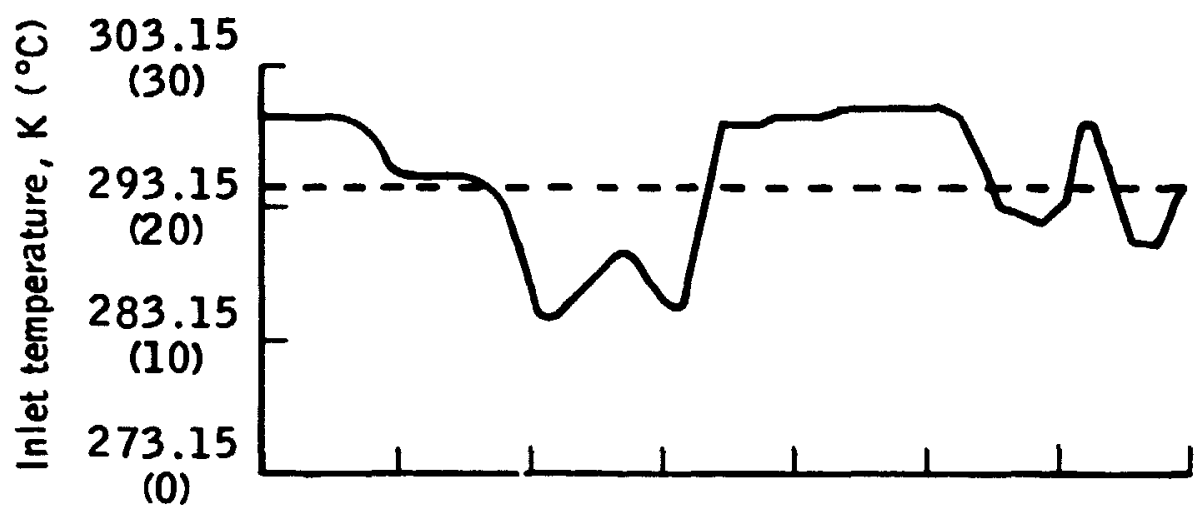

(d) LCG inlet temperature.

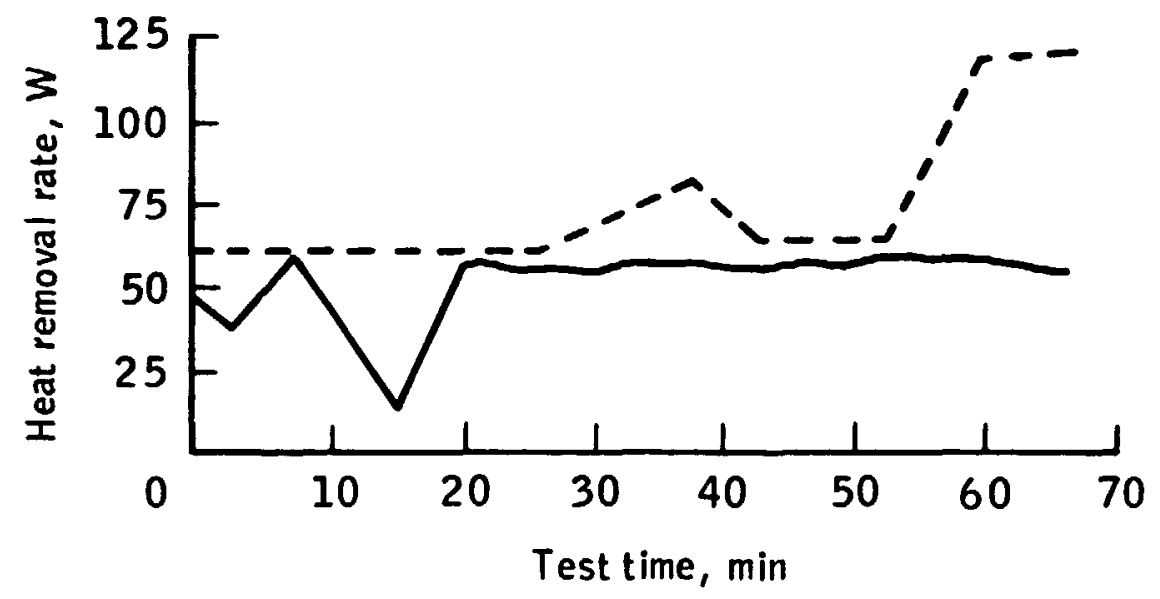

(e) Evaporative heat removal rate.

Figure 12.- Concluded. 


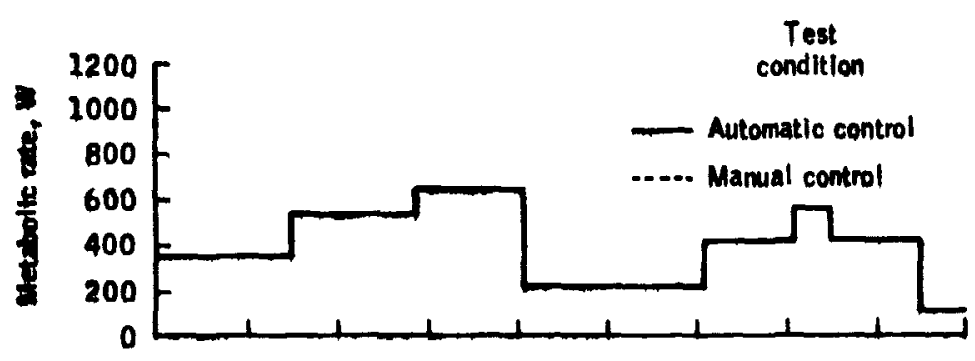

(a) Matabolic rate.

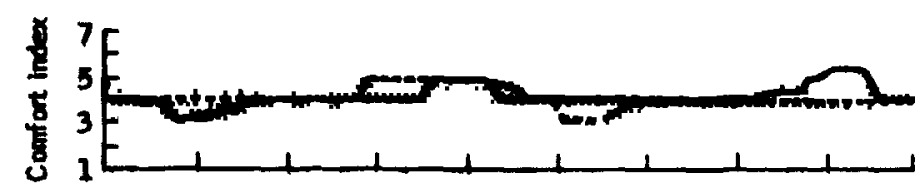

(b) Comfort index with comfort zone shaded.

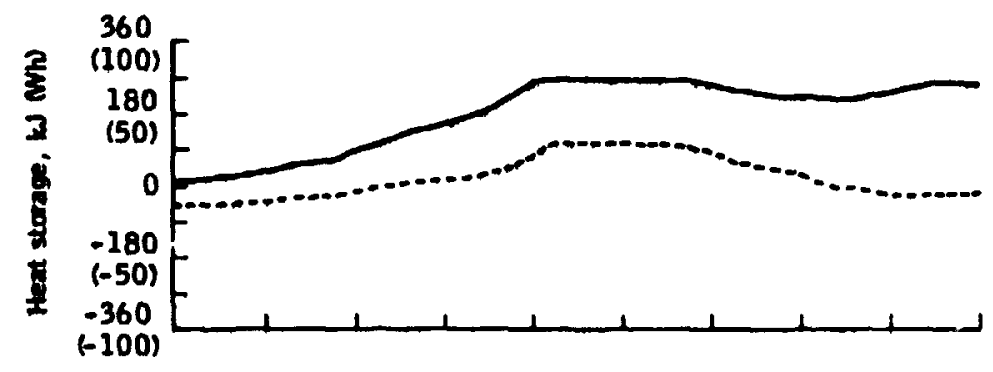

(c) Total body heat storage.

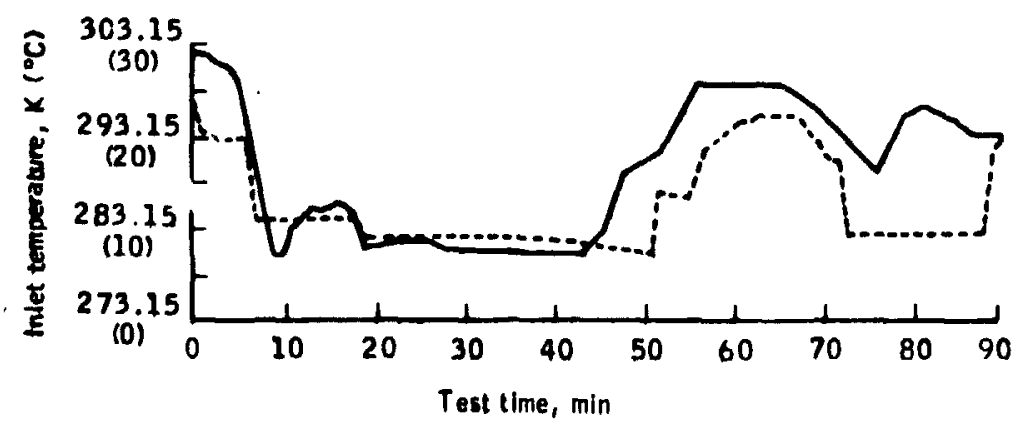

(d) LCG' inlet temperature.

Figure 13.- Automatic controller performance compared with manual control during test runs at the Skylab EVA proffle. 


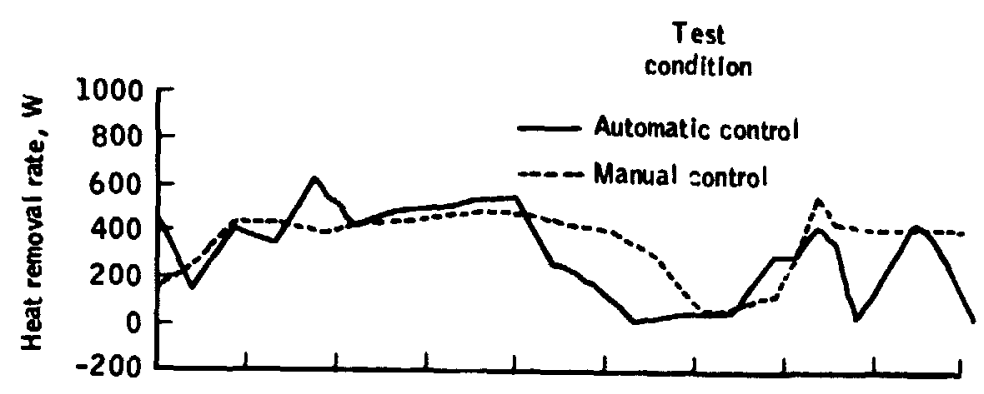

(e) LCG heat removal rate.

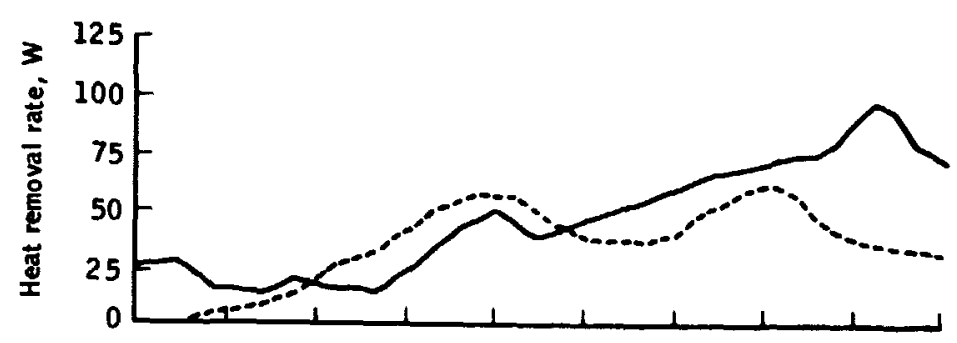

(f) Evaporative heat removal rate.

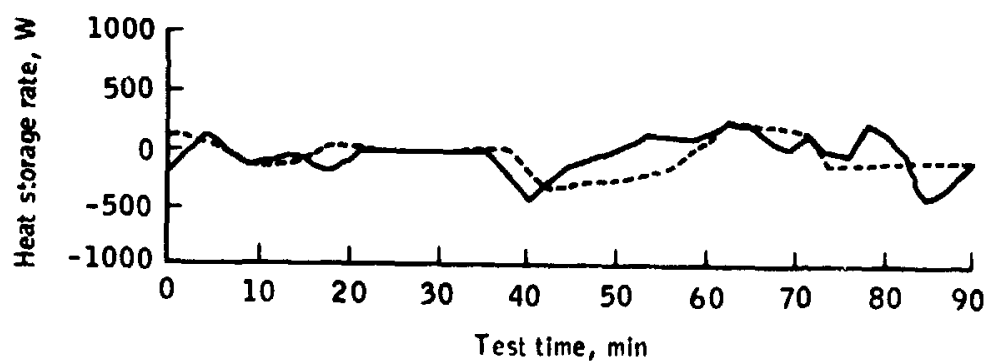

(g) Body heat storage rate.

Figure 13.- Concluded. 


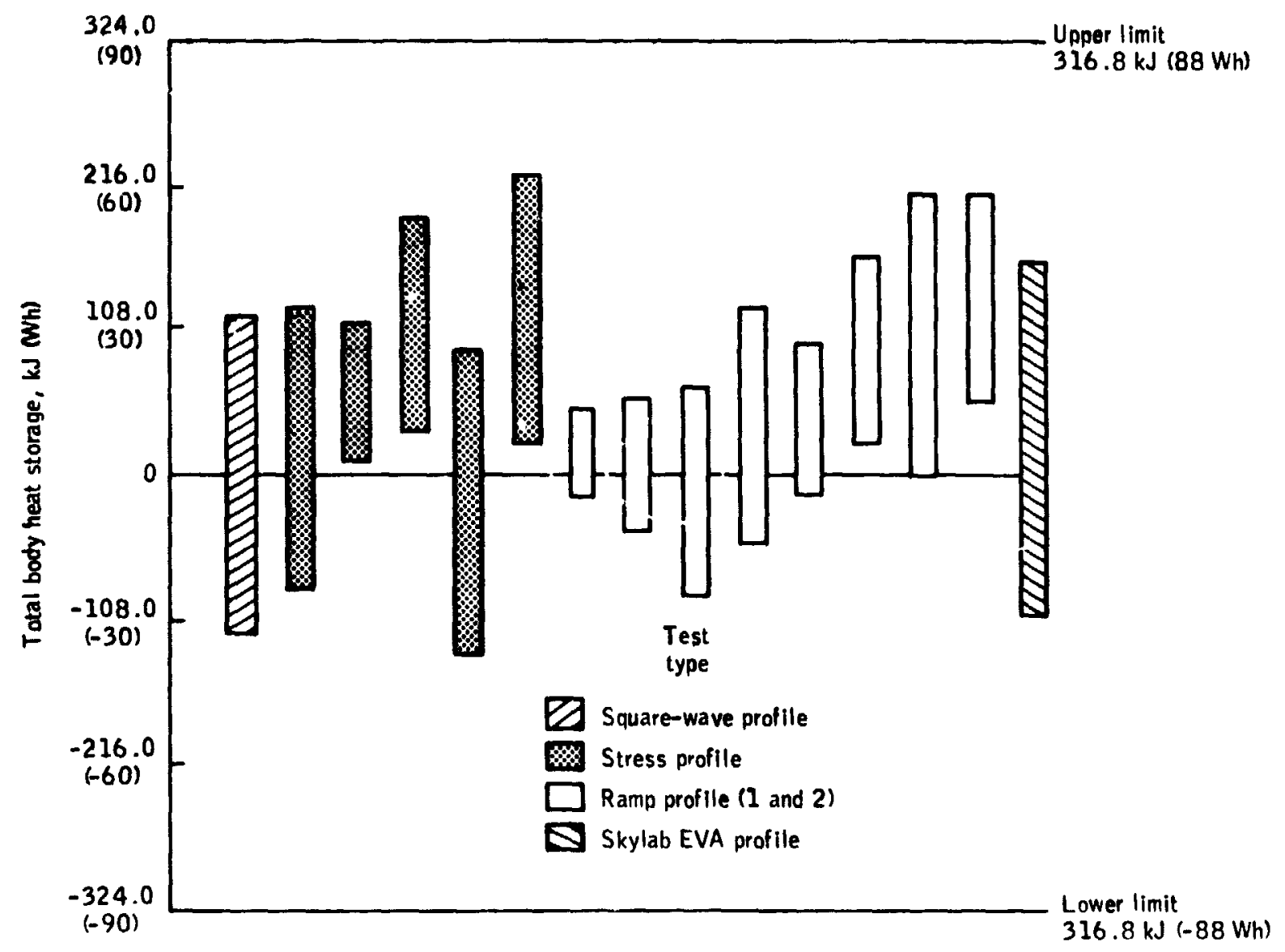

Figure 14.- Body heat storage extremes with controller. 


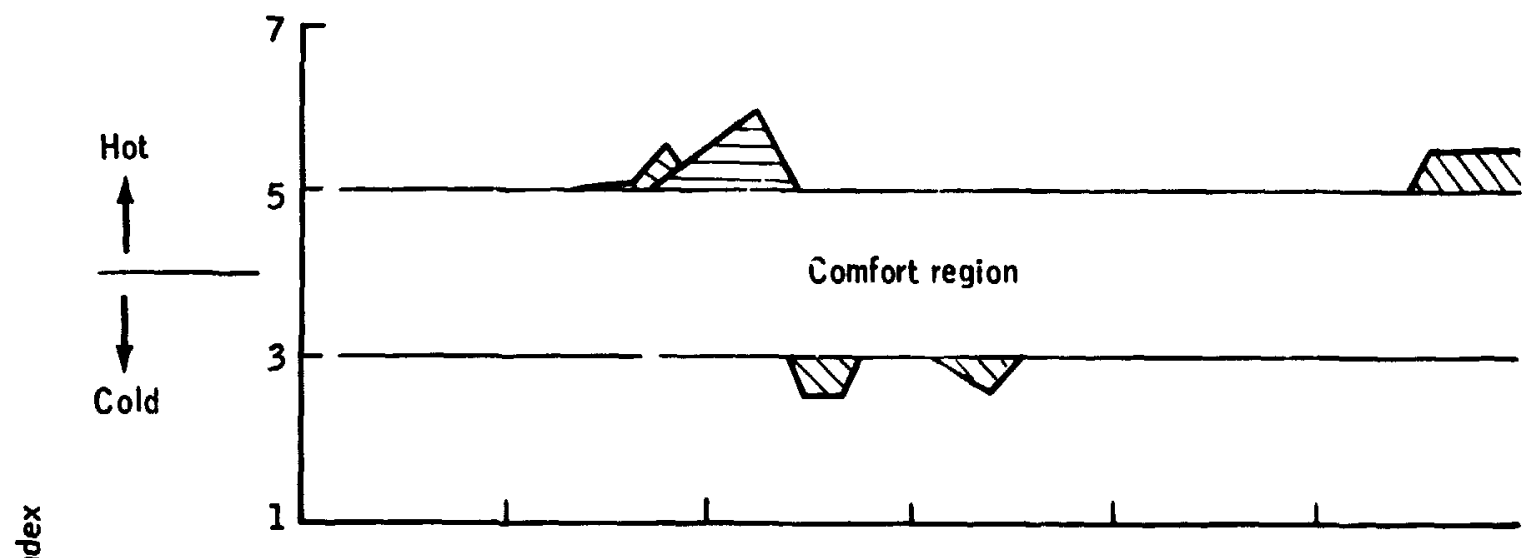

(a) With use of controller.

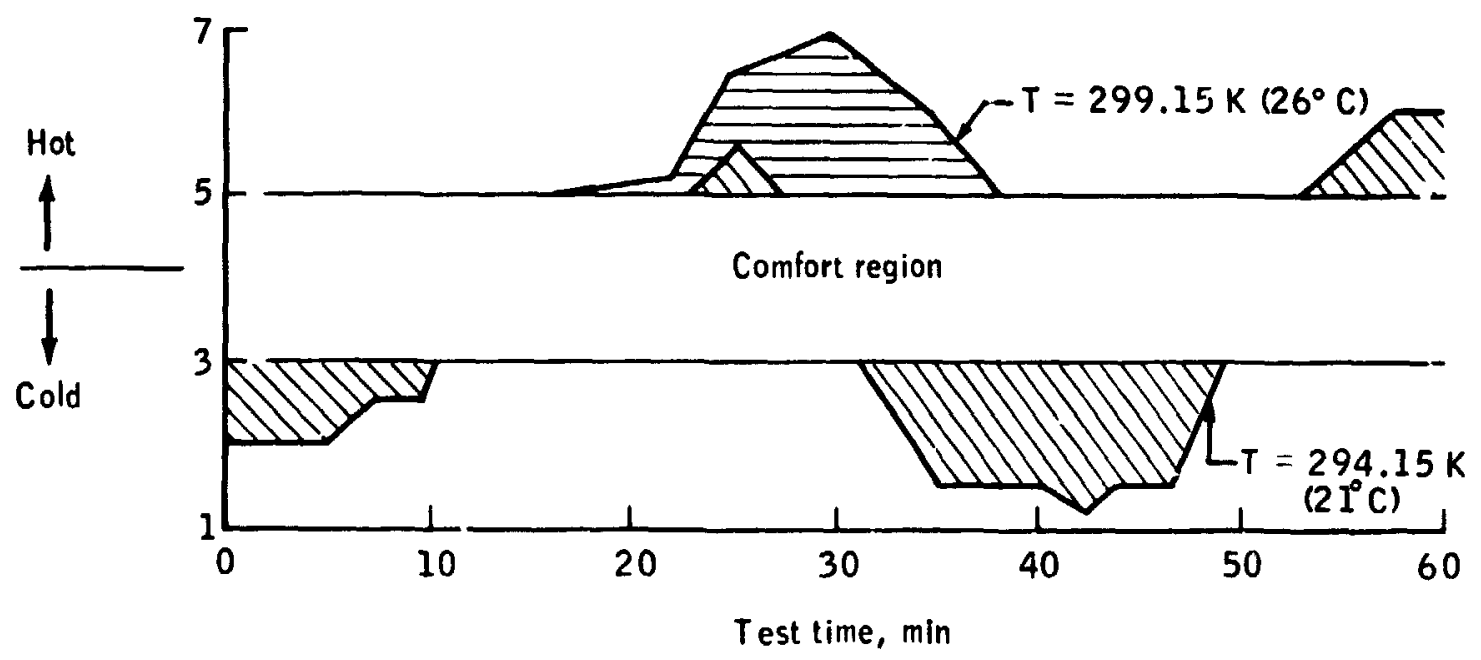

(b) Without use of controller.

Figure 15.- Comfort index results.

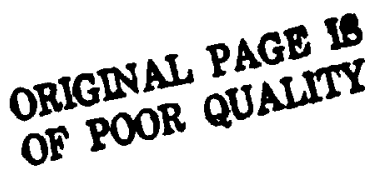




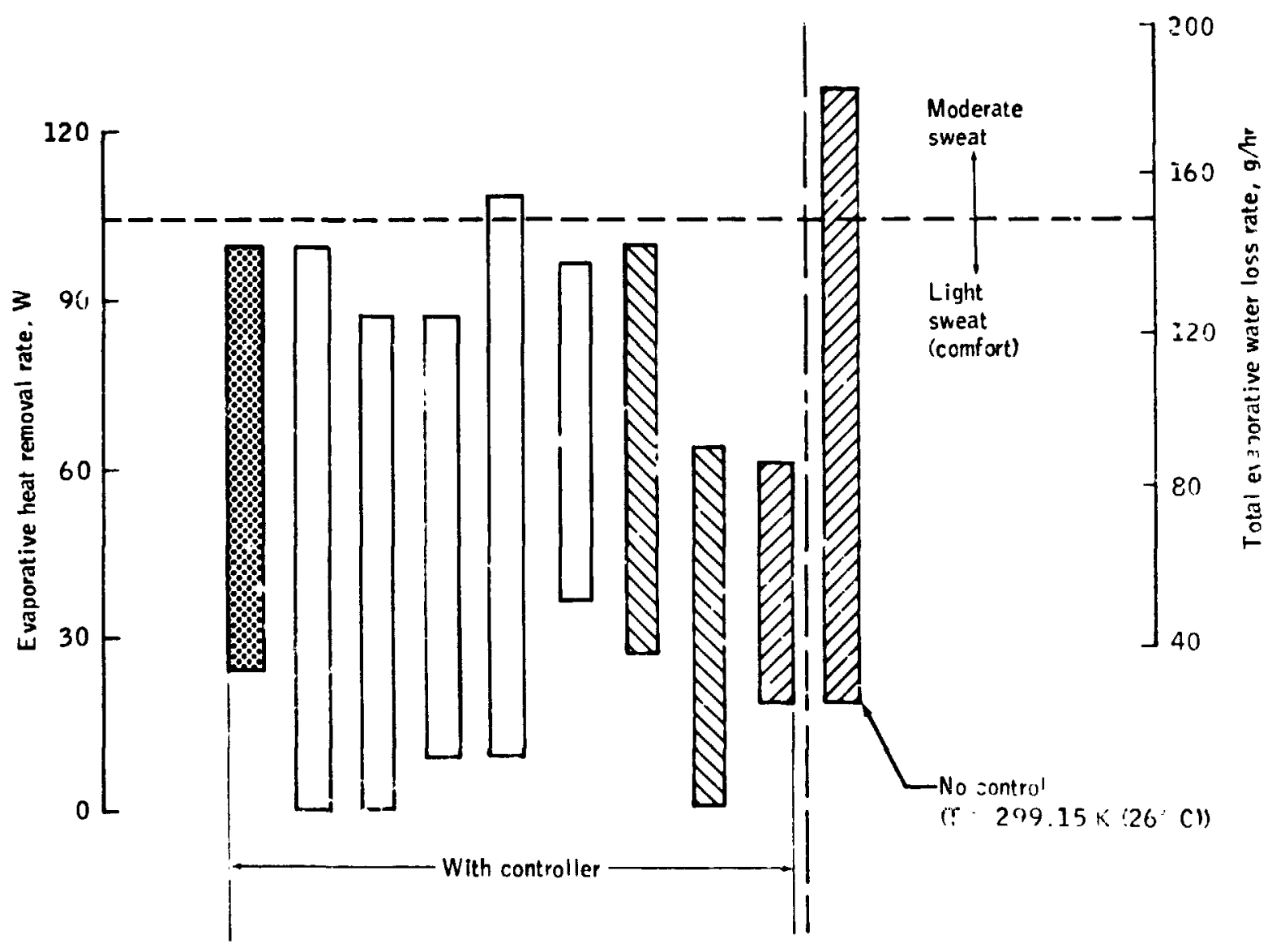

Fiqure 16.- Lritent heat extremes, with and withou't use of controller. 


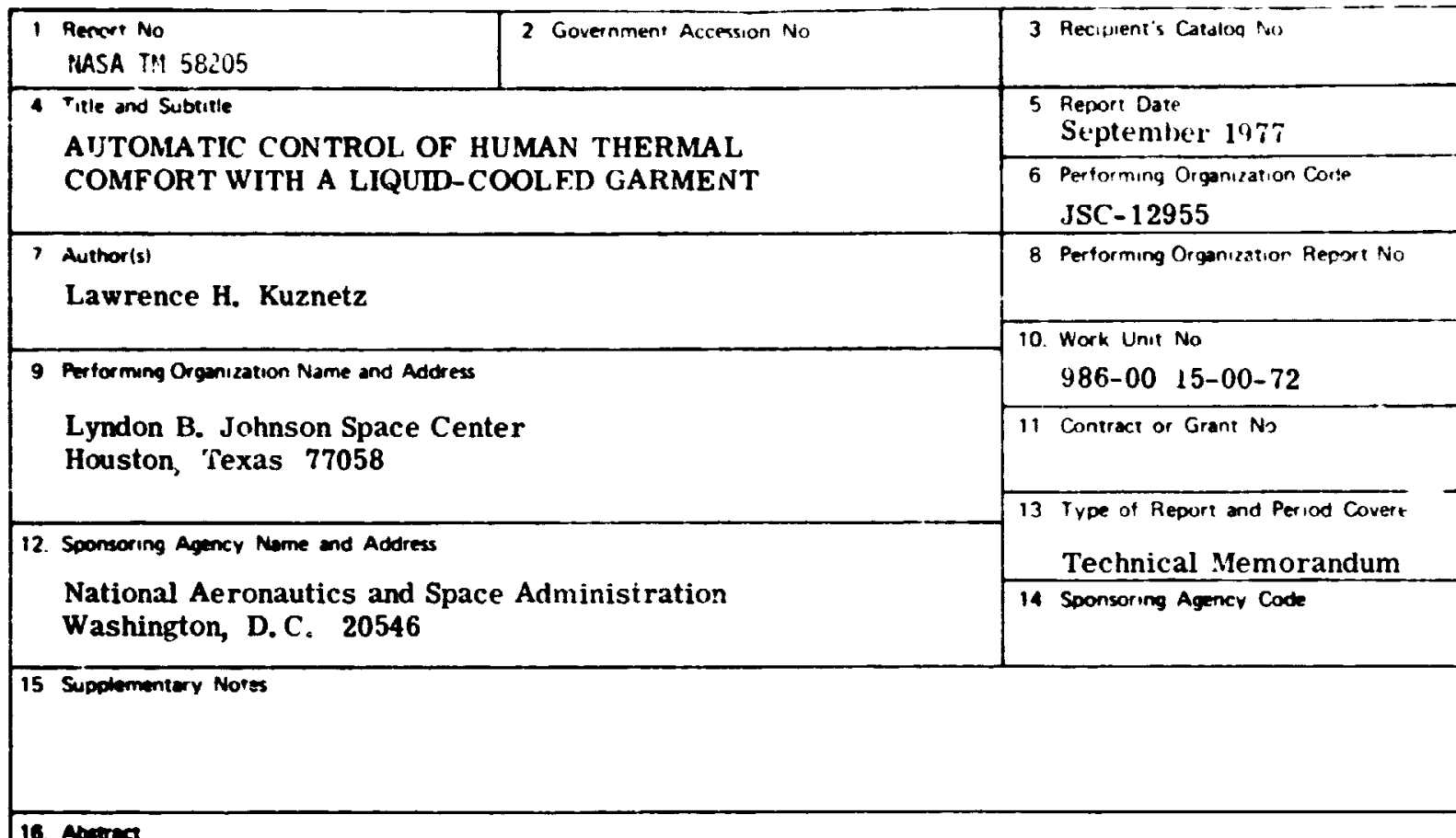

In the Space Shuttle Program, water cooling in a liquid-cooled garment will be used to maintain the thermal comfort of crewmembers during extravehicular activity; and a need exists for a simple conirol that will operate automatically to maintain the thermal comfort. A series of tests in this study verified the feasibility of such a controller that operates by measuring the tir perature difference of water going in and out of the garment. Data on three test subjects are included to support the conclusion that heat balance can be maintained well within allowable medical limits. The controller concept was also successfully demonstrated for ground-based applications and shows potential for any tasks involving the use of liquid-cooled garments.

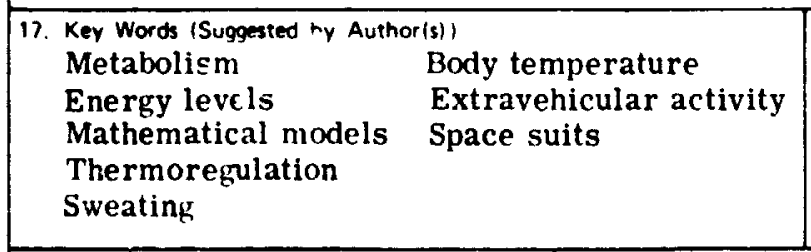

18 Distribution Statement

STAR Subject Category:

54 (Man, System Technology and Life Support)

\begin{tabular}{|l|c|c|c|}
\hline $\begin{array}{l}19 \text { Security Classif lof this report) } \\
\text { Unclassified }\end{array}$ & $\begin{array}{c}20 \text { Security Classif tof this page) } \\
\text { Unclassified }\end{array}$ & $\begin{array}{c}\text { No of Pages } \\
42\end{array}$ & $\begin{array}{c}\$ 1 / e^{\circ} \\
\$ 4.00\end{array}$ \\
\hline
\end{tabular}

- For sale by the National Technical Informatiun Service. Springfield, Virginia 22151 